\title{
El automóvil en la historia. Luces y sombras
}

\section{The automobile in history. Lights and shadows}

Gustavo Vega Delgado

Universidad Internacional del Ecuador, Ecuador

Ericka Gabriela Martínez Pastor

Universidad Internacional del Ecuador, Ecuador

Autor por Correspondencia: gvega@uide.edu.ec, ermartinez@uide.edu.ec

Fecha de recepción: 30 de Abril de 2017 - Fecha de aceptación: 30 de Junio de 2017

\section{Resumen}

Historiando algunos hitos del coche. El presente trabajo anhela acercarse con otros ojos al mundo de la formidable ingeniería del automóvil y sus impactos. Cita interdisciplinariamente y comenta algunos acontecimientos, épocas y personajes sobre el tema. Menciona aspectos de la historia y aborda algunos pormenores relacionados a las consecuencias de la universalización de este invento clásico y símbolo del siglo XX. Luces y sombras en relación al impacto del auto se presentan, teniendo en cuenta salud y ambiente. Énfasis en el Ecuador salpica con frecuencia la trama del artículo, sustentado a través de un estudio de campo con el fin de tomar más contacto con la realidad. Un nuevo trato humanista es obligatorio, a fin de superar la ambivalente relación hombremáquina.

Palabras clave: automóvil; historia; marcas; pilotos; carreras; salud; ambiente; placer; entrevistas; muerte; nuevo trato hombre-máquina

\begin{abstract}
Under an historic point of view, some key issues are related to the automobile. This paper approaches with other eyes to the automobile magnificent engineering world and its effects. It quotes inter disciplinary aspects and comments several facts, epochs and personalities about this theme. It mentions historic aspects and speaks on some detail in connection with internationalization consequences around this twenty century classic symbol invention. Lights and shadows regarding automobile impacts, are presented keeping in mind health and environment. Emphasis on Ecuador as a country is constantly settled along this article, reinforcing through a field approach in order to take more contact with reality. A new deal and attitude is compulsory in order to overcome dilemmas and the ambivalent relation man-machine.
\end{abstract}

Key words: automobile; history; marks; pilots; races; health; environment; pleasure; interviews; death; new deal man-machine 


\section{Introducción}

El presente trabajo se inscribe dentro del campo del medio ambiente, uno de los expresamente citados como preferentes para el Innova Research Journal de la UIDE Extensión Guayaquil, en donde se publica este paper. La presente investigación versa sobre el automóvil y su entorno, sus luces y sombras, abordado desde una perspectiva histórica. Dado que en donde se publica este aporte, pertenece a una Universidad que exhibe en su oferta académica la carrera de Ingeniería Automotriz, se consideró pertinente y apropiado publicar aquí precisamente una investigación bibliográfica sobre el automóvil y su entorno histórico, con el debido sostén de investigación de campo.

El trabajo se asoma con dos objetivos. El primero pedagógico educativo, aspira llegar en especial para estudiantes de Ingeniería Automotriz, para ofrecerles una perspectiva complementaria en su formación profesional. También sigue y persigue un segundo objetivo la presente publicación: abrir un enfoque humanístico sobre el automóvil, en donde perspectivas de la historia ligadas al medio ambiente, permitan que este trabajo lleve de la mano a lectores de las más amplias áreas del conocimiento, pues anhela enriquecer con una visión holística, el particular modo de enfocar el automóvil y sus múltiples rostros.

\section{Material y Métodos}

Los materiales para esta investigación se concentran en una recopilación bibliográfica actualizada sobre el tema, y la aplicación de una entrevista semi estructurada a informantes claves y calificados, para recoger datos e información más precisos que corroboren o aporten debate mediante investigación de campo sobre este trabajo. (Véase Anexo 1.) Énfasis se coloca en las realidades del Ecuador sin dejar referencias pertinentes a nivel mundial. Los métodos giran en torno a un review de la literatura afín, tomando referentes de los distintos tipos de automóviles, marcas y épocas. La historia siempre asiste el enfoque como una disciplina eje que atraviesa los distintos momentos de la perspectiva asumida. Para las citas se utilizó el sistema internacional APA. El paper pasó el filtro del sistema detector anti plagio URKUND, reportándose un 1\%, lo que según los parámetros es insignificante. Tal procedimiento sirve además en favor de la transparencia y la ética al servicio de la investigación. (Véase Anexo 2).

\section{El auto, símbolo de la modernidad.}

Un símbolo especial del siglo XX es el automóvil, solo quizá comparable al avión, la radio, el cine, la televisión, el internet. Los primeros ensayos del Ford modelo T representaron un impacto de proporciones en el mundo contemporáneo; Henry Ford, una rara combinación entre inventor y empresario dio en quiebra más de una vez antes de levantar cabeza. La declaratoria del Volkswagen escarabajo como el vehículo más emblemático del siglo XX, la furgoneta Volkswagen, casi fuera de circulación ya, fueron símbolos para los amantes del automovilismo.

\section{Íconos y leyendas de la memoria.}

Sin duda que es icónico el VW Escarabajo, pues para Latinoamérica su ensamblaje en Puebla, México y en Brasil, contribuyó para adoptarlo como suyo y darle una familiaridad única. 
Sin embargo debe también ser mencionado otro auto símbolo. El caso de la furgoneta Volkswagen tuvo tres etapas: la Transporter T1, la T2 y la T3. La T1 traía el parabrisas dividido, el motor atrás. La furgoneta T2 traía la versatilidad moderna para que sirva como campers, busetas, carros de carga, camionetas, doble cabina, de ejes largos para transportar madera. Canadá adquirió muchas para sus bosques. El modelo Samba incluyó más belleza y ventanas cenitales. El modelo Westfalia representó el icono clásico de un camper. Hasta 1967 se produjeron 1millón 800 mil unidades de la T.

Luego, la T3 colocó el motor adelante, enfrentó la competitividad, puso más velocidad pero perdió en identidad. Sin embargo todas las T, representaron un hito en la función y en la estética del automovilismo mundial. En Gran Bretaña tiene lugar la convocatoria más grande del mundo de los amantes de la VW T. Hay quienes se han dedicado hoy en día a rescatar de bosques, pantanos, graneros y lugares abandonados, dichas furgonetas, algunas en estado de franco deterioro; sin embargo con vocación y pasión han logrado recuperaciones, restauraciones o reconstrucciones impresionantes de dichos vehículos emblema. La T es probablemente la leyenda más grande de la historia del automóvil. (DeutscheWelle, 2017).

\section{Sofisticada estética.}

La alta tecnología unida a la estética de los vehículos especialmente italianos: Maserati, Ferrari, Lamborghini, crispa los nervios de los aficionados y asombra su más sofisticada tecnología colocada sobre carros portentosos. Íconos clásicos de toros de lidia indultados adornan los colores exultantes de las carrocerías de los últimos de los vehículos citados. La policía de Dubai adquirió múltiples unidades Lamborghini exhibiendo un insólito y suntuario gasto para su parque automotor a servicio de sus uniformados.

El nieto de Ferdinand Porsche ha inaugurado en enero del 2017 el 4to centro "Experience Center" en el mundo, en donde la adrenalina y noradrenalina, es decir la sensación de miedo e impulso, al momento de conducir autos altamente sofisticados, se lo haga bajo el apoyo de un tutor empoderado al lado de los choferes ávidos de exotismos.

\section{La gigante BMW y su pasado nazi.}

Cuando el iniciado en la experticia de los autos sofisticados, se deleita con la versión 4 de los M de los BMW, no imagina que atrás de técnica y belleza inusuales, reposan en el subconsciente de la fábrica tinieblas borrascosas. El historiador Joachim Scholtyseck, escribió en el 2011 una obra que rasgó las vestiduras al pasado: "El ascenso de los Quandt. Una dinastía empresarial". Un libro de más de 800 páginas. La misma familia Quandt, decidió abrirle los archivos confidenciales al historiador, para ventilar el pasado nazi de la familia.

En base de la misma tendencia: oxigenar el pretérito a partir de la auto confesión, así lo hizo el escritor Günther Grass, premio Nobel de literatura, quien confesó haber militado otrora en las juventudes nazis. El politólogo italiano Norberto Bobbio procedió de similar manera: reconoció públicamente haber formado parte en tiempos de juventud, de las camisas negras fascistas. 
El antecesor de la dinastía, Emil Quandt, fundó una pequeña fábrica textil en la localidad de Pritzwalk en Brandenburgo en 1883. (Tiempo atrás Juan Sebastián Bach se encargaría de universalizar el lugar, cuando pusiera en celebridad sus afamados conciertos denominados precisamente Brandenburgo) Fue para 1890 que el proveedor de tela firmó un contrato para la elaboración de los uniformes del ejército imperial prusiano. Su hijo Günther Quandt produjo un salto cualitativo: abundó en su imperio textil e incorporó a su haber plantas eléctricas y una fábrica de baterías.

Se enriqueció gracias a los miles de esclavos judíos que laboraban en sus fábricas y, gracias a la infame ley de "arianización" (en favor de la raza aria) que otorgaba el derecho de enajenar los bienes judíos, se hizo de fortunas judías desmanteladas, exponenciando su poderío financiero. Curiosamente los Aliados tras la guerra, no persiguieron a los beneficiarios de los nazis. No hubo un juicio de Nuremberg para los aliados nazis y menos en el campo empresarial. Murió en 1954 en olor a dinero y silencio a voces.

Sus hijos Harald y Herbert heredaron más de 200 empresas. La suerte construida por Herbert fue particularmente vertiginosa. Adquirió casi en banca rota en 1959 la empresa bávara de autos BMW y a contrapelo de lo que le recomendaron sus asesores, invirtió aún más en ella, alumbrando la emergencia del gigante automotriz en forma ya incontenible. Su viuda recibió en el año 1972 en que su esposo falleció, el 16.7\% de las acciones, Setefan su hijo, el 17.4\% y Susane, su hija, el 12.6\%. De un total de $46.7 \%$ que a la familia le pertenecía. (El País, 2015).

La viuda de Herbert Quandt, Johanna, fue la matriarca de mayor fortuna en Alemania hasta el 2015 en que murió: 31 mil millones de euros que heredaron sus dos hijos.

Susanne atravesó un escándalo de proporciones, cuando un gigolo suizo le amedrentó con publicar videos comprometedores de sus mutuos amoríos, a condición de que le pusiera en sus bolsillos 50 millones de euros.

La señora que llevaba el apellido Klatten de su esposo Jan, superó la extorsión y riesgo de estafa, denunciándolo a la policía, con el saldo en contra de ver desnudada su vida marital.

Susanne Klatten es sin embargo paradigma de una mujer emprendedora e innovadora. A los 19 años adquirió la empresa farmacéutica Altan y luego fue presidenta de SGL Carbon, clave en la fabricación de fibra de carbono, parte de la industria automotriz BMW.

Los Quandt han mimado con celo desde tiempo atrás el anonimato y la privacidad. Lejos de barullo y candilejas de los afortunados por el dinero y el poder, han acariciado el mayor sigilo familiar en sus vidas diarias -salvo por el escándalo de marras arriba citado. (El País, 2015).

Purgando las complicidades pretéritas de su antecesor con el genocida mundo nazi, ahora la familia Quandt, en cuasi total invisibilidad se dedica a contrapelo, a financiar obras pías y filantrópicas, en un intento quizá culposo por borrar las cicatrices de tiempos ominosos.

\section{Un recién llegado.}


Korea del Sur en una sola generación dio un salto cualitativo inusual: pasar de la extrema pobreza al más alto desarrollo tecnológico en su país, a pesar de haber pagado un alto costo humano medido por el inusual estrés académico de los koreanos y un súbito incremento inusitado de los suicidios.

Hyundai y Kia mejor le representan en el campo automotriz, mientras la japonesa Toyota sigue siendo la fábrica que más autos produce para el mundo.

En los últimos años la Policía nacional del Ecuador, patrulla sobre un relevante número de autos y jeeps de marca Kia. El grupo Eljuri es la firma nacional importadora y ensambladora tanto de Kia como de Hyundai koreanas. La marca Chevrolet norteamericana tampoco es ajena a la Policía pues también innumerables unidades fueron adquiridas al Grupo Eljuri.

En Korea la tecnología no sólo acolita los autos. LG impresiona. Samsung, es uno de los gigantes mundiales de la televisión y los teléfonos celulares. Se alista hoy a vender masivamente sus móviles S8 luego del fracaso estrepitoso tras la explosión sistemática de sus erráticos S7.

Lamentablemente la corrupción, común denominador de la sociedad contemporánea, no ha dejado inmune a Samsung: acusada de coimar al círculo político de la presidenta del país, corruptor y corrumpida debieron pasar por el banquillo de los acusados.

El jefe de Estado debió renunciar y el heredero de la fortuna koreana enfrenta aún con grilletes penalidades en proceso.

Park Geun-hye, es la destituida presidenta de Korea del Sur, acción ejecutada por el parlamento y ratificada por la corte de justicia. Hija de último dictador sur koreano, fue elegida por una abrumadora mayoría. Enfrenta ahora el karma de haber sido destituida por corrupción.

Lee Jae-yong, vicepresidente, heredero y nieto del fundador de la empresa Samsung fue interrogado en el caso denominado "Rasputinesca sur coreana", así llamada Choi Soon-sil, íntima amiga de la destituída y encarcelada presidenta, quien habría presionado con la entrega de dinero a la gigante de las telecomunicaciones, para que el gobierno de su aval para la fusión de dos de sus filiales.

En mayo del 2017, la depuesta Park fue sustituida en elecciones libres por quien perdió antes, frente a una abrumadora victoria de la hoy encarcelada.

\section{Detroit.}

Lo que otrora fue el templo más emblemático del imperio automotriz, la ciudad de Detroit, en donde se acantonaron las marcas norteamericanas provocando el mayor boom de la historia, hoy varios de los lugares de la citada ciudad de Michigan, padecen de altos índices de desempleo, dando el aspecto de un cuasi cementerio tras la resaca de un éxito durable y esplendoroso. En parte la transnacionalización de las empresas y la maquila que produce repuestos y arma vehículos en otros países como México, Brasil, Argentina, han provocado serias crisis en las fábricas matrices. 


\section{El embrujo de la motocicleta.}

Las tecnologías de las motocicletas tienen otra historia. Lambretta, Vespa, cuyo término viene de "avispa" por el parangón de sus respectivos sonidos-zumbidos, dieron un impacto impresionante en su estética y función, posibilitando inclusive que la mujer por primera vez conduzca motocicletas reventando los patrones patriarcales de la sociedad. Como aquella escena del cine de 1953, Roman Holiday, en donde Gregory Peck y Audrey Hepburn posan frente a una motocicleta, teniendo como fondo al Coliseo o a las escalinatas de la plaza España de Roma, en donde las motos italianas eran parte obligada del libreto.

El creador de la motocicleta Lambretta fue Piaggio que utilizó motores de arranque de aviones reciclados de la Segunda Guerra Mundial para instalarlos en sus motos ${ }^{1}$. En el Ecuador, los sacerdotes salesianos generalmente italianos, popularizaron la Vespa, ágil medio de transporte para los discípulos de Don Bosco. El ex presidente de Uruguay Pepe Mujica, con su habitual austeridad aparte de conducir un viejo Volkswagen escarabajo azul de la década de los 70, itinerantemente se transporta a lomo de una motocicleta Vespa. Y ello, en el 2017.

Japón con Honda y Yamaha fueron pioneras en los modelos de motocicletas enduro, trial y motocross. Los fans y adictos a la Harley Davidson norteamericana han constituido en el mundo verdaderas subculturas de los amantes de esta especialísima y esplendorosa motocicleta. En la Segunda Guerra mundial el side-car se popularizó: una motocicleta abordada por un soldado, con un vaso comunicante a un pequeño auto que permitía la ocupación de otro soldado, éste sí con las manos liberadas para disparar, se esparció en los campos de batalla.

Tricimotos, herencia de las furgonetas de 3 ruedas que aparecen desde 1924, son usadas en Trento, en especial las Goliath F400 con su motor bajo el asiento para mejorar la estabilidad, las que aún se encuentran entre los viñedos desde 1947.

En el norte de Perú y en la costa ecuatoriana, tanto como en el Asia, abundan las tricimotos: 3 ruedas que sobre una motocicleta innovada llevan 2 a 3 pasajeros en su cajón cubierto o no, o pequeñas cargas que hacen la vida plácida en la mitad de penurias y escasez.

En torno a las motocicletas, una especialidad propia de países de inviernos duros y largos, son las motocicletas de nieve. Skies en vez de ruedas permitieron, mitad utilidad, mitad deporte, deslizar su velocidad sobre la nieve y tanto mejor cuanto más espesa era.

\section{Europa, alter ego de Norteamérica.}

Europa por su parte contribuyó en su historia en contraste con Norteamérica con vehículos más pequeños y versátiles y dueños de una identidad más particular. Francia, Gran Bretaña, Suecia, Italia, alumbraron marcas muy especiales: Peugot, Austin, Land Rover (especialmente su modelo Defender si nos seduce el safari), Volvo, Fiat, por citar tan solo unos ejemplos.

\footnotetext{
${ }^{1}$ Referencia brindada por el licenciado Pablo Barriga Cordero, cuya familia es ítalo-ecuatoriana.
} 
El Citroën DC2 es el equivalente al VW Escarabajo en la producción francesa. Armado en base a un diseño minimalista, su uso y forma hicieron historia. Faros fuera de la carrocería, lona semi descapotable, hasta 1990 todavía se lo podía prender con manivela. El Fiat 500 es la contrapartida italiana en el caso de los autos populares europeos.

De vuelta al Citröen 2CV se lo dio en llamar primero despectivamente "Patito Feo", pero luego su sobrenombre se re funcionalizó entusiastamente en forma positiva al extremo de hacerse abiertamente popular.

Varias empresas fusionaron sus capitales y tecnología como la Mercedes Benz o la Audi; en este último caso, cuyos cuatro círculos superpuestos en el emblema de marca representan sus raíces matrices

\section{El auto al servicio de un amo, el despotismo totalitario.}

Alemania Oriental tras la cortina de hierro provocó un carro muy difícil de conseguirlo, cuyos beneficiaros tenían que estar en una larga lista de espera por años hasta obtener una unidad. Los autos Trabant hoy son vehículos muy escasos que aparecieron antaño con tecnología soviética y hoy son cotizados para museos y coleccionistas.

Sin embargo, a la vez estuvo ligado fuertemente dicho vehículo a la ideología del espionaje y la represión de la policía secreta de Alemania del Este: la truculenta STASI. (Donnersmark, 2006)

Hubo vehículos relacionados especialmente a la ideología nacional socialista de Hitler, emblemáticos y especiales que fueron obsequiados por su particular símbolo a otras dictaduras y gobiernos aliados de la órbita nazi. Clásicos descapotados para que el carisma populista de Hitler o Franco desfilaran en posición de pie sobre sus autos para la ovación de sus respectivas multitudes.

El Generalísimo Francisco Franco ostentaba su poder encaramado en uno de ellos, su marca emblemática fue un Mercedes G4. En la década del 70 del siglo pasado el dictador español prefirió transportarse en los actos oficiales en un Cadillac Fleetwood.

Un reflejo condicionado que nos lleva a la perversidad de las guerras mundiales y sus efectos fatales tiene que ver con las sirenas despedidas de los vehículos piloteados por agentes de la GESTAPO, la policía secreta nazi. Sirenas irrepetibles de otras marcas y sabores todavía llevan de la mano al oído y a la mente a lo que significó la barbaridad de las confrontaciones bélicas en la historia. Películas basadas en el Diario de Ana Frank, difundieron por el mundo el perverso sonido de las sirenas de autos nazis ululando sobre una Amsterdam ocupada.

\section{La guerra inventa sus autos.}

Hablando de conflictos, confrontaciones y guerras, los Jeep Willis aportaron identidad en el frente de batalla. Unos descapotados, otros con cubierta de lona, color verde oliva, afin castrense generalizado, son parte de las inclemencias y la dureza de los conflictos armados. Hoy 
en día el modernizado Jeep Grand Cherokee aún recrea en parte sus símbolos tradicionales, aunque con un sabor reciclado distinto, propio de épocas de paz y bonanza.

\section{Terror sobre ruedas.}

Con el avance del tiempo, a finales del siglo XX, el vehículo sirve de herramienta de extremismos y excesos. Múltiples coches-bomba han explotado especialmente en Oriente Medio, para expresar unas veces rebeldías reprimidas y otras, efectos de la rabia fanática actual en lugares de profunda crisis.

En el caso de América Latina, un acontecimiento en septiembre de 1976 de ingrato recuerdo ocurrió con el asesinato de Orlando Letelier en Washington, en donde vivía exiliado. Letelier, economista, ex ministro y político, miembro de la Unidad Popular de Salvador Allende. Su muerte se derivó de la explosión de una bomba activada a control remoto colocada en la parte inferior del vehículo en el cual circulaba, atentado organizado como parte del Plan Cóndor, herramienta de la ultra derecha continental para exterminar las izquierdas latinoamericanas. (Biblioteca Nacional de Chile, 2016)

Dos camiones se lanzan en estampida intencionalmente contra la multitud; en Niza el 14 de julio de 2016, día histórico de Francia y en Berlín, en las navidades del 2016. Los vehículos han servido también como vehículos -valga el retruécano- del terrorismo internacional. En marzo de 2017 un islamista radical alquila un vehículo en Gran Bretaña y enviste a los vía andantes que circulaban en las veredas del puente sobre el río Támesis frente al Parlamento británico en Londres; nuevamente muertos y heridos frente a un acto terrorista.

En mayo del 2017, aparentemente un enajenado mental lanza su vehículo sobre los peatones en el Times Square de Nueva York. En algunos casos similares, la investigación determina que se trata de extremistas religiosos que perpetran dichos comportamientos impresionantes; en otros casos, se trata de locos violentos, contaminados de situaciones parecidas que se han dado en varias partes del mundo.

Accidentes fatales en autos, ligados a personajes de la historia abundan. Citemos el caso de solo tres: la bailarina Isadora Duncan ${ }^{2}$, la actriz y princesa Grace Kelly ${ }^{3}$ y la Princesa Diana de Gales ${ }^{4}$ del Reino Unido.

\footnotetext{
${ }^{2}$ La bailarina y coreógrafa norteamericana, iniciadora para muchos de la danza moderna, Isadora Duncan, murió estrangulada en 1924 en Niza cuando su larga estola-chalina bordada se engargantó fatalmente por el viento en la rueda de un auto convertible circulando a velocidad, conducido por el joven mecánico italiano Baenoit Falcheto.

${ }^{3}$ Grace Kelly, artista de cine, ganadora de un Oscar, musa del glorioso cineastaAlfred Hitchcock, comprometida con Rainer de Mónaco y princesa luego, murió en los vericuetos de Montecarlo, paradójicamente en la misma carretera en donde rodó con Gary Grant tiempo atrás, Atrapar a un ladrón

${ }^{4}$ Diana de Gales, hija del cuarto barón de Fermoy, se casó con el príncipe Carlos, tuvo dos hijos, años después se divorció. Fue apreciada por todo el mundo por su ayuda humanitaria. Murió en un accidente automovilístico al ingresar al Puente del Alma en París, dentro del cual chocó contra una columna después de que el conductor quiso evitar a unos paparazzi.
} 
Un acontecimiento de especial luto para la cultura y el pensamiento relacionado con el automóvil ocurrió con el premio Nobel de literatura 1957, el argelino-francés Albert Camus.

Murió en 1960 mientras viajaba de copiloto en un auto deportivo exclusivo Facel Vega FV3B. El conductor, Michel Gallimard, sobrino del editor de sus libros, a una velocidad de 180 kilómetros por hora, se salió de la carretera estrellándose contra un árbol, mientras una intensa llovizna provocara quizá la ruptura de un eje y la explosión de una llanta del auto.

Camus y Gallimard murieron en el acto. La mujer de Camus, cinco días más tarde. Sus dos hijos salieron ilesos. Su perro desapareció. En el lugar del accidente se encontraron manuscritos de su nueva obra inconclusa: El primer hombre. En el bolsillo del premio Nobel se hallaron boletos no utilizados de tren a París, pues a última hora el accidentado habría cambiado de opinión. Como en el relato de Las Mil y una noche, "Muerte en Teherán", habría partido huyendo de la muerte y sin embargo en forma paradojal vino a encontrarla.

Dos días antes, Camus, escritor del absurdo existencial, había comentado que la muerte frente a un auto del ciclista Fausto Coppi en las vías era una cosa idiota. Se trataría de un comentario quizá pre monitorio. La prensa al día siguiente se encargó de jugar con las palabras en forma irónica, se diría incluso cruel, señalando que la muerte de Camus, el escritor del absurdo, era en efecto un absurdo. (ALTIMA, 2016).

Obras de gran calado existencial pertenecen a la pluma de Camus: La peste, el extranjero, el hombre rebelde, marcaron hitos en la literatura y el pensamiento.

\section{Nostalgias y saudade a lomo de auto.}

Mientras los Jaguar y los Rolls Royce fueron los autos selectivos de las élites económicas, los Mustang mejor encajaron en los apegos juveniles y deportivos de nuevas y emergentes generaciones. El caballo cerril de las praderas norteamericanas cedió su nombre e imagen para la marca estética de los Mustang.

Recuerdos icónicos de los autos descapotados se recrean en la memoria cuando el presidente John F Kennedy fuera baleado por Lee Harvey Oswald en el año 1963, mientras saludaba al público sobre un Lincoln Continental Convertible en las calles de Dallas, Texas.

Un 10 de agosto reciente, el Informe a la Nación, que por deber el gobernante ecuatoriano debe rendir en el Palacio Legislativo, se regodeó de la parafernalia y el oropel de un emblemático, sólido y rotundo Hammer, que transportaba hacia la alfombra roja de la entrada del recinto, a un presidente de la República de pie sobre el vehículo portentoso, calzando gafas ahumadas y teniendo como telón de fondo acústico las notas épicas de "Patria Tierra Sagrada", que contribuían a crear una atmósfera de boato y piel de gallina en el público estupefacto.

La subcultura de los Yuppies se encargó de convertir el auto en un elemento especial de su identidad derrochista en favor del despilfarro y la ostentación: así como no repetían un traje en su vestuario por cada día del año, exhibían un vehículo diferente a su haber por cada día de la semana. Los Yuppies, colectivo identitario ligado al consumo refinado, representaron la 
contrarréplica a las subculturas Hippie y Punk, cuyos patrones de comportamiento diferían abiertamente.

\section{El auto que trabaja y el que pasea.}

Una especialidad muy original en la historia del automóvil significa la aportación en favor de vehículos de transporte pesado. Difícil es imaginar la construcción sin volquetas y otra maquinaria pesada propia de épocas en donde las carreteras y autopistas se tejieron como telarañas sobre la geografía del mundo. Buses de doble piso como en Londres y Vancouver, le ofrecieron identidad a sus ciudades. Escolares y colegiales a bordo de busetas amarillas, se popularizaron en el mundo ofreciendo especificidades para el transporte estudiantil.

Campers, motorhomes y tent trylers, transportando a familias de aficionados por la naturaleza y el camping para exorcizar de su itinerario de viaje, a hoteles y restaurantes, provocaron tecnologías y estéticas singulares sobre verdaderas casas rodantes en donde dormitorios, sala-comedor, cocina y baño, se daban cita en un solo vehículo. De aquellos, quizás el diseño más emblemático tiene que ver con el camper en burbuja de los años 50 del siglo XX, cuyo diseño de líneas curvas semejaba más a un zeppelín que a un carro. Su modelo Airstream aún en nuestros días, bien entrado el siglo XXI, conserva su belleza.

El advenimiento de los vehículos 4x4 significó un hito en la historia del automovilismo. La tracción sobre 4 ruedas permitió que el lodo, la nieve, y otras penurias de carreteras tercermundistas sean superados. Los $4 \mathrm{x} 4$ hoy cargan el símbolo de la fuerza, poder y prestigio, sin dejar la vanidad de sus dueños.

\section{Un auto y una conexión religiosa.}

Hay relaciones esotéricas o al menos herméticas entre ciertos autos y las religiones.

Una de las religiones cuna de la humanidad es el Zoroastrismo. Poco practicada en Irán hoy en día, pero sin duda matriz de las grandes religiones monoteístas que nacieron posteriormente en el Cercano Oriente.

"Ahura Mazda", según Zaratustra o Zoroastro, es el señor de la sabiduría, es el único dios que debe ser adorado. El término y concepto de Mazda, en cuanto símbolo de sabiduría, es parte de la nomenclatura de los automóviles japoneses de marca Mazda precisamente, término tomado de los ancestrales zoroastristas.

El fundador de la empresa Mazda, Jujiro Matsuda, fue un inventor múltiple y genial de Hiroshima. Aficionado a la espiritualidad decidió que todos sus autos reciban el nombre de Mazda, término tomado de Ahura Mazda, que en la lengua Avestan servía para nombrar al dios de la sabiduría, la inteligencia y la armonía.

Azor Ahai es un semidiós del zoroastrismo que triunfa sobre la oscuridad. Personaje que sirve de inspiración a su vez en la serie de televisión "Game of Thrones" de George R.R. Martin. 
La celebrada serie para el cine, "La Guerra de las galaxias" acumula en su ideología de fondo conceptos claves de la religión de Zoroastro.

Los conceptos arcaicos de luz y oscuridad, fuego y tinieblas, dios y demonio, los conceptos binarios ligados al día del juicio final, el infierno y el paraíso, no son conceptos originalmente cristianos, judíos o islámicos, sino que parten de Zoroastro (en griego) o Zaratustra, el profeta iraní que tal vez vivió entre el 1000 y el 1500 a.C. y que quizá fue contemporáneo de Ciro el Grande.

Rafael en su impresionante pintura "La escuela de Atenas", pinta a Zaratustra sosteniendo un globo brillante. Dante en "La divina comedia" al tratar sobre el paraíso y el infierno, quizá solo repite, brillantemente cierto, lo que que Arda Viraf siglos antes ya había descrito profusamente sobre estas dos antípodas de la religión a la luz del zoroastrismo.

Zararustra, es el mismo filósofo del cual se sedujeran Frederick Nietzsche y Richard Strauss, al escribir el primero para la filosofía y el segundo para la ópera, sus respectivos clásicos: "Así hablaba Zaratustra".

La partitura musical de Strauss le sirvió a Stanley Kubrick para colocarla como tema musical de su película científica y profética, "2001, Odisea del Espacio". Ciertamente que en el caso de Nietzsche su posición atea le permite combatir los símbolos religiosos, incluidos los de Zararustra, para decretar que 'dios ha muerto', y que según su ácida concepción, se asiste al 'crepúsculo de los dioses'.

¿Qué decir de W.A. Mozart que en su última ópera compuesta, " La flauta mágica", incorpora claros mensajes y nomenclaturas zoroastristas, aparte de masónicas en su trama? Sarastro, el sacerdote y mago que tanto el músico austríaco como el autor del libreto, Schikaneder, le representan con abundancia de símbolos y ritos seguidamente binarios: la lucha entre la luz y la oscuridad, la prueba del fuego y del agua, la bondad y la maldad.(Bekhrad, J, 2017).

Posiblemente hablando de Mazda, en cuanta sabiduría, el mejor término equivalente en griego es el de Sofía.

\section{Y el pontífice también se contamina.}

El Papa-móvil es un vehículo emblemático del Vaticano, elaborado con variantes en cada país anfitrión que recibe al pontífice, que en sus viajes repetidos, ha dado al auto su propia identidad y especialmente seguridad, para evitar posibles atentados- como el ocurrido con Juan Pablo II-. Son los Papa-móviles vehículos de blanco impoluto -como mitra y sayal del heredero de San Pedro- con vistas panorámicas, para ver bien y sobre todo ser bien visto, pero elaboradas a la vez con vidrios antibalas.

\section{Limosinas, la pasión por lo exótico.}


Limosinas extravagantes forman parte del escenario exótico, con sabores de portento al servicio de la opulencia mundial. Magnates y artistas del celuloide son parte de sus usuarios. El narcotráfico prefiere también conducir a sus capos atrás de vidrios ahumados y sobre las ruedas de estos vehículos casi tan largos como un zeppelín. Blancos o negros son sus colores clásicos. Muertos importantes no son la excepción, quienes son transportados en posición horizontal sobre limosinas rumbo a campos santos.

Facultades de ingeniería automotriz en algunas instituciones como la Universidad Internacional del Ecuador por su parte, han elaborado mediante el concurso de sus profesores y estudiantes su propia limosina con ingenio y perspicacia en favor del proceso de enseñanzaaprendizaje, puesto que los estudiantes, amantes del automovilismo son motivados para continuar en esta carrera a pesar de no tener un conocimiento suficiente previo, debido a las diferentes innovaciones y oportunidades que les ofrecen para su formación a pesar que haya cierto grado de deserción ${ }^{5}$.

\section{La Habana, Cuba.}

Carros nostálgicos se los puede palpar de primera mano en Cuba. Autos de los 40 y 50 restaurados y moviéndose en las calles de La Habana son una rutina: viejos Chevrolet Impala, Oldsmobile y tantos otros en impresionantes condiciones, que en otros lados y tiempo atrás que fueron parte de la chatarra del reciclaje, fueron sin embargo emblema de supervivencia de la isla que dejó en impronta esta forma de vivir y transportarse, cuando las condiciones económicas son adversas y no es posible traer a raudales autos nuevos.

En otras partes del mundo, un símbolo histórico superviviente de otras épocas es el Opel Kadette, marca alemana con especial diseño y appeal.

Pichirilos y carros de madera: cuando lo lúdico juega.

Las carreras de "pichirilos", se han convertido en tradición jocosa de festividades ligadas a la exhibición y el ingenio de carros viejos, que por sus limitaciones, arrancan el agrado hilarante de los espectadores durante su perfomance.

No se confunda el socarrón término de "pichirilo", con otro que la metáfora de la historia acuñó cuando al periodista Alejandro Carrión -Juan sin Cielo- le hartaron de heces, tras un linchamiento propiciado por pesquisas. Nadie sabe a precisión si ordenado el ex abrupto por el entonces presidente José Velasco María Ibarra, o más probablemente por su entonces ministro de gobierno, Camilo Ponce Enríquez. Hecho bochornosamente conducido por los "pichirilos", 2016)

Alejandro Noboa y Modesto Gómez, que viabilizaron la estercolaria orden. (Vallejo,

Una derivación alegre y plena de habilidad psicomotriz y destreza audaz, consistió siempre en el Ecuador de las barriadas pobres, el concurso de coches de madera. Piloteados por

\footnotetext{
${ }^{5}$ Información obtenida a partir de la entrevista al doctor Diego Pérez, decano de la Facultad de Ingeniería Automotriz de la UIDE
} 
guambras hábiles, sobre creativas plataformas que a duras penas conectaban a volantes removibles y a ruedas -más que llantas- suicidas, volaban cuesta debajo de la ladera en donde el final era símbolo de victoria u hospital seguro.

La UIDE a través de su facultad de Ingeniería Automotriz, año tras año organiza en réplica lo dicho un concurso similar, aunque con bastante más tecnología, sin exorcizar de todo el riesgo y los accidentes en la mitad del jolgorio.

\section{Joie de vivre.}

El concepto del auto en relación a restaurantes y alimentos y bebidas, fue expresión de la joie de vivre desde los años 60 del siglo XX. Muchachas condimentadas de mini faldas servían charoles atados a ganchos estratégicos a calzar sobre los vidrios semi abiertos de convertibles y tantos modelos de autos. Hamburgers y refrescos así se servían con hedonismo apetente, directamente a los autos golosos, apostados en estacionamientos alrededor de restaurantes especializados en esta innovación y snob. La moda norteamericana se esparció por el mundo con la velocidad de un Ferrari.

En el Ecuador la moda y el snobismo de las food trucks se han esparcido con sabor más a comida rápida que a innovación culinaria. Una suerte de servicio a domicilio sobre ruedas, de camiones remodelados para la cocina, sirviendo alimentos para fiestas, reuniones y eventos

La iniciativa de los food trucks además de mostrarnos una nueva tendencia culinaria, su popularidad trajo consigo una sobrepoblación de los mismos, lo que provocó una variación en el modelo de este negocio hacia lo que hoy se le conoce como food parks. Son establecimientos fijos que acogen varios contenedores o plazas, en un lugar más amplio, salubre, con una mejor atención al cliente, en donde además se pueden apreciar movimientos culturales y de arte en un lugar en el cual los emprendedores gastronómicos puedan ofrecer sus servicios, aunque también tengan sus contras como el pago de arriendo o el horario de trabajo; es un negocio que va en crecimiento; Quito posee más de 35 plazas con una creciente de 700 nuevas marcas, como La Pradera Food Garden o La Platea. (El Comercio, 2017).

En algunos países liberales como en Suecia, relaciones íntimas entre parejas en el auto, son aceptadas con tolerancia. A manera de anécdota, la policía sueca solía sugerir mitad ironía mitad en serio, que no olviden de poner freno de mano al vehículo.

Fueron épocas en donde la recreación ligó el cine con el auto: los autos cinemas fueron una constante para adolescentes y parejas jóvenes de los años 70 y 80 del siglo XX especialmente. Sobre mega pantallas en parques al aire libre, se proyectaban películas a cientos de espectadores estacionados en sus respectivos automóviles. Las butacas eran las de sus mismos vehículos.

La sexualidad ligada al auto significó más allá de una extravagancia. La intimidad sexual a bordo de autos se popularizó entre los jóvenes, en tiempos en donde no habían asomado aún los moteles propios para que privacidad, anonimato y placer vayan de la mano a la hora de una cita por horas. 
Si está prohibido a no, tener sexo abordo de autos, depende de cada país, su legislación y en especial sus costumbres morales y religiosas. En el caso del Ecuador aparentemente no estaría prohibido (El Comercio, 2016.) Sin embargo el miedo al escándalo, el riesgo de inseguridad y posibles afrentas sexuales a la pareja o solo a la mujer, por parte de viandantes delincuenciales, pueden ser motivaciones para detenciones, extorsiones y corruptelas por parte de la policía.

\section{Lujos extintos.}

En cuanto a los automóviles lujosos Oldsmobile, cabe el recuerdo de una añeja corruptela. El ministro Ponce Enríquez, antes de ser presidente de la República y entonces estuviere en el gabinete de Velasco Ibarra, fue denunciado por haber importado para el sector público, decenas de estos estéticos y costosos carros, con expresa disposición de liberación de los correspondientes derechos aduaneros. La maña estuvo en que por gestión de algún asesor de los que nunca faltan, a la vuelta de la esquina de la administración política, varios de aquellos Oldsmobile fueron a dar en su paradero al garaje de personas privadas.

\section{El Ecuador y sus primeros autos.}

Mientras la danza de la tecnología y la opulencia circulaban en países desarrollados, el Ecuador llegando tarde a la industria y la tecnología del mundo, país agrario, con resabios feudales y de capitalismo temprano, con fuertes dosis remanentes de esclavismo del campo y la ciudad, recién aunando esfuerzos de corte-y-pega con partes importadas y un aporte más artesanal que industrial creó por primera vez el vehículo de marca Andino. Valioso aporte de AYMESA que a pesar de una versión rústica dio un campanazo para ofrecer vehículos de trabajo, no de paseo en un Ecuador atrasado en la modernidad. El papel empresarial de Carlos Arízaga Vega en esta primera gestación y alumbramiento de vehículos ecuatorianos, debe ser reconocido ${ }^{6}$.

Actualmente Maresa y otras ensambladoras arman carros de patente extranjera dentro del país, aún a costos muy altos en comparación con aquellos países que han logrado acuerdos internacionales mediante tratados de libre comercio. Firmado un tratado de libre comercio con la Unión Europea y, entrando en vigencia el primero de enero de 2017, para exoneración de autos, todavía hay que esperar entre 7 y 10 años, pues un 5\% menos inmediato parece no hacerle ni cosquillas al monto de desgravamen.

Carlos Álvarez Gangotena, compró el primer auto que llegara a Quito; adquirido en la Exposición Mundial de París en 1900. Lo trajo en barco a través del Atlántico, por el estrecho de Magallanes -no operaba aún el Canal de Panamá- y por Guayaquil a Babahoyo, en cuyas bodegas debió esperar hasta que un crudo invierno permitiera recién en 1901 llevar las cajas que encerraban las partes del flamante primer auto en la historia del Ecuador, a lomo de guandos -los atléticos y explotados arrieros indígenas andinos- y a lomo de mulas hasta la capital, similar a la

\footnotetext{
${ }^{6}$ Carlos Arízaga Vega, político y empresario, fue candidato a la presidencia del Ecuador por el partido conservador. Víctima de la desaparición de uno de los vuelos de la empresa aérea SAETA que cubría la ruta QuitoCuenca en 1979.
} 
forma de conducir por las inescrutables breñas andinas, los pianos de cola europeos y mobiliario fino.(Automagazine.ec,2017)

El presidente de entonces, Leonidas Plaza Gutiérrez, lo inauguró junto a su edecán, mientras hacía de chofer el mecánico que armó el vehículo, Manuel Bucheli y hacía de acompañante, el dueño del mismo. Se trataba de un auto francés De Dion-Bouton vis-a-vis, modelo 1900, con motor de 402 cc, $3.5 \mathrm{hp}, 2$ velocidades y una de reversa, alcanzando 20 kilómetros por hora; los asientos estaban tapizados con piel de elefante. Vis-a-vis significaba cara-a-cara, es decir que el asiento del chofer y su copiloto veía de frente al de los otros dos pasajeros. La compañía francesa elaboraba 400 autos de su marca por año para el 1900.

En Guayaquil, la familia Guzmán Aspiazu importó el primer auto que circulara en el primer puerto en 1900. (Ecuadorprofundo, 2017)

El primer auto que llegó a Cuenca, lo importó el empresario y político Federico Malo Andrade en 1912 quien en su vida había sido el primer presidente del Banco del Azuay, diputado, senador, gobernador, educador, rector del colegio Benigno Malo ${ }^{7}$. El automóvil importado de Francia fue un Clemant Bayard. (Avance, 2012)

\section{Izquierda versus derecha: cuando jacobinos y girondinos del automóvil disputan el volante.}

Los jacobinos, el ala radical de la postrevolución francesa, se sentaban en el parlamento a la izquierda, mientras los girondinos, el ala moderada de la política, lo hacían a la derecha. Tal el origen de los símbolos ideológicos, en el diapasón de la sociedad internacional de los países con sus bancadas y banderas políticas.

En el mundo del automóvil también existen bandos y tendencias irreconciliables entre izquierdistas y derechistas. Los jacobinos y los girondinos son aquí los que defienden la ubicación del volante, a la izquierda o a la derecha de sus carrocerías.

Al Ecuador, más vinieron con el volante a la izquierda, a excepción de aquellos que se importaban desde Gran Bretaña, cuya tradicional práctica de llevar el volante a la derecha se debió a su historia distinta y diferenciada, basada en el uso de los carruajes antecesores del auto, en los cuales el conductor que llevaba el látigo para acicatear y azuzar los caballos lo hacía con la mano derecha. La circulación obligatoria por la izquierda prevenía de agredir con el látigo a peatones.

Al revés, la circulación por la derecha lo impuso Napoleón -que era zurdo-. Lo que le resultaba mejor al momento del movimiento de carrozas y caballos.

\footnotetext{
7 Según informantes ligados a la familia, el pequeño puente peatonal que une la Escalinata de Cuenca a la antigua casa del doctor Julio Malo Andrade, hijo de Federico Malo, ubicada entre la calle Larga y la Escalinata, tiene aún como sostén parte de los ejes y la carrocería del primer auto llegado a Cuenca. Durante varios años dicho puente daba acceso a un departamento de arriendo. Entre otros lo usó en alquiler el filósofo argentino Horacio Cerutti, profesor a la sazón en la Universidad de Cuenca, hoy profesor en la UNAM de México. Posteriormente dio acceso por largo tiempo al Wunderbar.
} 
Las tendencias a conducir por la derecha o la izquierda, hay que leerlas más atrás en la historia: especialmente en la vía Apia y otras de las múltiples redes de carreteras construidas, para dar abasto a carruajes y caballerías, en tiempos del imperio romano.

\section{La clase social tiene marca.}

La secuencia cronológica de la invención y uso de los vehículos obligada por el transporte, partió las clases sociales en estratos, cuya expresión visible de corte significó el auto.

La secuencia de ascenso social de menos a más nivel, suponía el peatón, el que conducía una carreta, el que viajaba en tranvía y en lo más alto de la alcurnia, el que poseía un automóvil. Los autos y el incremento vertiginoso de los autos obligaron a municipios y Estado a promulgar ordenanzas y leyes paulatinas y progresivamente más innovadoras para regular el transporte, en donde buses y tranvías junto a taxis y autos privados cambiaron radicalmente el paisaje urbano del mundo.

\section{La bicicleta o la renuencia al cambio.}

Siempre hubo algo de renuencia en soportar los cambios vertiginosos que el automóvil imponía. Por ejemplo, no era raro observar en la década de los años 50 y comienzos de los 60 del siglo XX, a pesar de los irreversibles cambios motorizados, que diversos médicos de tradición aún realizaban visitas a domicilio a sus pacientes sobre la montura de sus bicicletas y, cuyos maletines médicos negros y clásicos, cabalgaban bien fijados sobre la parrilla trasera de la montura.

En el caso de Cuenca, los doctores Leoncio Cordero Jaramillo y Timoleón Carrera Cobos, que a la vez fueron decanos de la Facultad de Ciencias Médicas de la Universidad de Cuenca, así practicaban dos veces al día su visita hipocrática y citas ambulatorias a sus enfermos.

Tendencias consistentes en popularizar la bicicleta en el mundo tienen sabores exitosos. Holanda y Dinamarca particularmente son de los países en donde el uso diario de la bicicleta se lleva la palma y la guirnalda. China, antes, más que ahora, tenía a sus ciudades plagadas de miles de bicicletas. La cultura ciudadana en favor de cultivar el respeto desde los choferes de los autos a los ciclistas, es todavía una tarea cuesta arriba en países del hemisferio sur.

\section{El paisaje urbano cambió para siempre, ¿vino el auto para quedarse?}

En el Ecuador de comienzos del siglo XXI los remolinos de vehículos circulando en sus ciudades han cambiado el paisaje y el espacio especialmente urbanos. Varios municipios han emprendido para contrarrestar su exceso en políticas y ordenanzas en favor del peatón y de la bicicleta. Guardando las diferencias de tamaño es asunto complejo el tránsito y seguridad no solamente en las ciudades grandes si no en las intermedias.

Riobamba, Ambato, Santo Domingo de los Tsáchilas, Quevedo, Ibarra, padecen de situaciones parecidas. Quito, Guayaquil y Cuenca han provocado ordenanzas para, previo a la matrícula de los vehículos, decretar la obligación de una revisión técnica vehicular para vigilar la 
seguridad del funcionamiento de partes claves de los vehículos y la vez para el control de la emisión de gases.

Cuando eventualmente existen paros y huelgas de taxistas y camioneros, buscando generalmente elevación del costo de los pasajes, las ciudades vuelven a respirar un clima casi bucólico en donde la eliminación del smog y el ruido permiten al peatón circular libremente a prueba de máquinas y abdicar, aunque con graves riesgos para la modernidad y la vida ciudadana, del uso de vehículos a doquier.

En el Ecuador, las ventas siguen priorizadas en favor de la marca norteamericana Chevrolet, la cual vendió en el 2015 un 51\% de los vehículos del mercado, mientras que en el 2016 lo hizo con el 46\%.La marca coreana Kia la misma que vendió en el 2015 el 10\% del mercado, en tanto que subió al 14\% para el 2016. La también coreana Hyundai vendió el $7 \%$ en el 2015 y subió discretamente al $8 \%$ en el 2016. Toyota se mantuvo tanto para el primero como para el siguiente año con un idéntico 5\% del total. La Great Wall china subió discretamente del 3\% al 4\%, del 2015 al siguiente. (El Comercio, 2017).

A pesar de que en los últimos años, la crisis financiera nacional ha producido impactos en la venta de vehículos, cabe mencionar que el grupo Eljuri que distribuye autos Chevrolet y coreanos, entre otros ítems dentro de una red numerosa de empresas comerciales, está constando como la empresa número 3 de entre las más relevantes del país. La empresa General Motors consta en séptimo lugar, la importadora Tomebamba en el número 30, a pesar de que esta última no solo se dedica a la venta de vehículos. Adicionalmente Corporación Casa Baca dedicada a la venta de autos nuevos y usados, consta en el número 48, medida siempre por las tributaciones al Sistema de Rentas Internas "SRI". (Campaña, I.2017)

Un factor importante que existe en el Ecuador es que posee tres regiones: costa e insular, sierra y la selva amazónica. Quito por ejemplo que se encuentra en la región sierra está situada a $2.800 \mathrm{mts}$ a nivel del mar y otras ciudades interandinas oscilan entre los $2.200 \mathrm{y} 2.400 \mathrm{mts}$. Muchos elementos que componen la industria automotriz dependen de gran parte en estas características regionales, por ejemplo en la misma venta de vehículos en la que Guayaquil que se sitúa al nivel del mar, tiene el mayor porcentaje de automóviles circulando por sus calles, ya que se encuentra en la región costa debido a la mayor presencia de oxigeno los motores de los automóviles reaccionan de una manera más efectiva, por lo que es un valor agregado para esta ciudad en cuanto a ventajas comparativas del estudio de la carrera Ingeniería Automotriz ${ }^{9}$.

Las concesionarias, se reservan mucho la información sobre el avance de la tecnología, puesto que cada marca llega al país con más innovaciones, lo que es una desventaja para las carreras de Ingeniería Automotriz del Ecuador, en este caso de la UIDE, ya que genera una falta de actualización de conocimiento, lo que impide que se tenga a la mano las herramientas suficientes para una enseñanza eficaz y de primera mano ${ }^{10}$.

\footnotetext{
${ }^{8}$ Casa Baca, es una de las empresas de compra venta de autos nuevos y usados. Consta entre las 50 primeras empresas ecuatorianas según declaración de impuestos.

${ }^{9}$ Datos obtenidos mediante entrevista a Edwin Puente, Coordinador de la carrera Ingeniería Automotriz UIDE extensión Guayaquil.

${ }^{10}$ Información obtenida de Andrés Castillo, coordinador de la carrera de Ingeniería Automotriz de la UIDE Matriz, mediante entrevista.
} 


\section{El vértigo de la velocidad.}

Gilles Villeneuve y Ayrton Senna, campeones mundiales de la Fórmula 1 que sucumbieron en la pista representan el agridulce de la más alta tecnología automotriz al servicio del deporte. Senna perecido en los vericuetos de San Marino (Biografías y Vida, La Enciclopedia Biográfica en Línea, 2017) y Villeneuve que luego de su inmolación en el asfalto de Bélgica, diera su nombre patronímico al autódromo de Montreal, sede del Grand Prix Du Canadá. Su lugar natal fue en efecto la provincia de Quebec ${ }^{11}$.

El piloto alemán más exitoso de la historia, Michael Schumacher en forma contradictoria a la esencia de su carrera en la fórmula 1, es otro de los grandes exponentes de vértigo de la velocidad en las pistas. Sin embargo, no pereció como tantos otros en el ejercicio de su peligroso trabajo profesional, sino que fruto de un fatal accidente mientras esquiaba en los Alpes franceses, su impacto le condujo a un coma irreversible que devino luego de un tiempo largo en muerte inevitable en el 2016.

Las escuderías de los grandes premios son verdaderas transnacionales de la Fórmula 1: Mac Laren-Honda, Porsche, Lottus, de las más sonoras. La propaganda ligada a las "partes” de los autos representa una industria exitosa. Firelli, Good Year, Shell y su poder petrolero, Phillips Car Stereo y Marlboro, esta última que siempre se cuela en la publicidad del deporte mundial en cualquiera de las especialidades, a pesar de la cínica contradicción entre tabaco, salud y deportes.

Los deportes de alto riesgo han sido espacios en donde la publicidad mítica y hasta dañina ha sido tierra de conquista. La bebida Red Bull creada por el austríaco Dietrich Mateschitzs, ha sido demostrada que la presencia en su fórmula del aminoácido taurina y de la glucoronolactona, pueden producir grave riesgo en la salud de los consumidores. Sin embargo el marketing se ha impuesto. (Omicrono, 2017).

\section{Cuando el alcohol conduce.}

Un complejo problema que liga la ingeniería mecánica automotriz a la medicina y la salud tiene que ver con el conducir vehículos automotores bajo el consumo de alcohol etílico. Los efectos mayores se ven en jóvenes varones entre 18 y 25 años cuyas consecuencias son fatales, pues sumado al exceso de velocidad representan las principales causas de siniestralidad no solamente en el Ecuador sino en el mundo. (Organización Mundial de la Salud, 2017)

Diversos estudios han demostrado que las mujeres producen menos accidentes fatales conduciendo vehículos en contraparte con sus pares varones; algunos otros estudios han encontrado que accidentes menores son provocados más en mujeres; sin embargo los fatales son más patrimonio de los hombres. En algunos países los hombres cometen cinco veces más infracciones que las mujeres. (El País, 2017).

Según apreciaciones en la vida cotidiana y en diálogos con mecánicos automotrices, las mujeres suelen con más frecuencia que los hombres sin embargo, afectar la caducidad temprana

\footnotetext{
${ }^{11}$ Le consta al autor principal de este trabajo por haber vivido varios años en Montreal.
} 
del sistema del embrague en los vehículos de trasmisión manual. Quizá la preocupación y tensión emocional mientras manejan, les induce a que inconscientemente mantengan presionado excesivamente el pedal del embrague con su pie izquierdo, lo cual contribuye al mayor desgaste de esta parte esencial de los vehículos con transmisión manual.

En Arabia Saudita es un tabú que las mujeres conduzcan autos. Basada en la Purdah, un conjunto de prácticas desde el protagonismo masculino para prevenir el honor de las mujeres, las penalidades en el caso de incurrir en infracciones así señaladas suelen ser drásticas y abochornantes.

Líbano tiene algunas libertades algo más permisivas para las mujeres, en comparación a otros países árabes. Por ejemplo, libanesas pueden sin extrema censura salir a bares y discotecas entre mujeres, lo que sería considerado una grave afrenta al Islam.

La lucha por la igualdad de las mujeres en general en países árabes es cuesta arriba aún en el largo proceso inequitativo entre géneros.

En el caso del Ecuador, cuando mujeres pioneras empezaron a conducir vehículos, desataron anatemas y marginaciones ligadas al prejuicio de la vida alegre. Judith Vega, Blanca Morla y Victoria Delgado, en el caso de la tradicionalista y conventual Cuenca de los años 40 del siglo pasado, siendo de las primeras damas que se pusieron atrás del volante, debieron sortear las censuras y prejuicios propios de la religiosidad fanática.

A pesar que existe discriminación hacia las mujeres que estudian o trabajan en el campo automotriz y que son varias las que llegan a puestos de supervisión, como también de gerencia, la ciudadanía aun no toma en cuenta suficientemente de que las mujeres profesionales, son capaces por sus características más cuidadosas y detallistas de incursionar en esta rama con otras perspectivas y valor agregado sobre la visión de los varones profesionales, según la apreciación de la profesora de ingeniería automotriz Sandra Chasi.

Por su parte, investigaciones de campo obtenidas por el decano y profesor Diego Pérez, mencionan que los varones, al tener una socia mujer ya sea en estudio o trabajo, brindan hacia ellas un sentimiento de protección pese a que el mundo automotriz sea primordialmente "cosa de hombres". En cuanto a conductoras de vehículos la evidencia demuestra que las mujeres exhiben accidentes de menos gravedad y magnitud ${ }^{12}$.

En Alemania no hay límite de velocidad. En el resto de Europa y América del Norte, sí; una puja de intereses entre los productores de autos y los ciudadanos juega una balanza en las decisiones.

En Ecuador en el año 2016, se produjeron 250 mil muertes en las carreteras según la policía, de las cuales más de la mitad fueron jóvenes (Teleamazonas, 2017). Se debe básicamente a que no se tiene la cultura de conducir con responsabilidad, por esta razón el país se encuentra en séptimo lugar en todo el mundo y en segundo lugar en Latinoamérica con más catástrofes por

\footnotetext{
12 Testimonio recopilado a la docente Sandra Chasi de la carrera de Ingeniería Automotriz de la UIDE, por medio de entrevista
} 
causa del tránsito. La campaña que se formó junto con COVIAL contra los accidentes de tránsito logró que se disminuyeran los siniestros, pero lo que se requiere es una educación para todos los usuarios viales y que se pueda llegar a la conciencia sobre seguridad vial ${ }^{13}$.

\section{Buseros, taxistas, chulíos.}

Los mejores taxistas del mundo son los londinenses. En varios seguimientos internacionales así se los ha evaluado. Las razones: seguridad, honestidad, cortesía, conocimiento.

En países como el Ecuador, si se quisiera ubicar el aprecio ciudadano por los choferes profesionales, pronosticaría un muy bajo nivel. En países como México, el policía por ejemplo se ubica en una de las más reducidas escalas de aprecio social.

Difícil tarea la de capacitar a los choferes profesionales. Exceso de velocidad, conducción bajo el efecto del alcohol etílico, irrespeto al peatón y a los ciclistas, grosería y falta de estilo en el trato, criminalidad culposa o dolosa en las vías, son la constante.

Los valores humanos son de los campos más ausentes en ellos. El lenguaje mímico y verbal, de los más deficitarios.

Los asistentes de los buses, mejor conocidos como "chulíos", son un grupo demográfico especial. La vida laboral les ha obligado a tener reacciones rápidas y a actuar a la defensiva para no dejarse engañar.

Generalmente son púberes, casi niños o adolescentes, que deben enfrentarse a un mundo violento. Su conducta para contrarrestar el riesgo de timo, ausencia de pago de las tarifas y más brusquedades ciudadanas, han desarrollado en ellos estados de alerta y conductas agresivas constantes. Diestros al motejar, enrostrar apodos, vejámenes, insultos y señas obscenas desde su iniciativa, solo responde a comportamientos también violentos de la sociedad en contra de ellos.

Carlos Michelena, el irónico actor de teatro de parque en El Arbolito en Quito, ha representado con fino humor el efecto del maltrato de buseros y chulíos a los pasajeros.

Muchos de los taxistas y choferes de buses y volquetes, no son dueños de los vehículos que conducen. Ello les hace vulnerables ante los propietarios y también por otro lado les provee grados distintos de irresponsabilidad en su tarea cotidiana. Una suerte de subempleo determina en ellos angustia y ansiedad y, por la precariedad con la que su situación laboral les precipita, su conducta como choferes profesionales deja mucho que desear.

Los transportistas tienen por otro lado un importante nivel de poder ciudadano, pues frente a huelgas y paros por el incremento de pasajes y otras reivindicaciones gremiales, pulsan el poder político con alcaldes y gobiernos locales o nacionales con fuertes dosis de conflicto.

\footnotetext{
${ }^{13}$ Comentarios brindados por el Director Ejecutivo de COVIAL, Víctor Jiménez
} 
Paros de transportistas ha tumbado gobiernos. Recuérdese el paro nacional se la rama en Chile de Salvador Allende, que junto a otras condiciones externas e internas precipitó el golpe de Estado de Pinochet.

Un asunto sobrecogedor ocurrido a fines del 2016 -en esencia ya mencionado en otro lugar de este trabajo- cabe citarlo con otro detalle en homenaje a los buenos conductores. Un chófer de nacionalidad polaca fue secuestrado por un terrorista en Berlín y obligado a cederle el volante para lanzar el enorme vehículo sobre la multitud que atestaba los mercados navideños. Hubo señales inequívocas de lucha y resistencia por parte del chofer antes de ser asesinado por el delincuente fanático. Una campaña internacional de solidaridad se levantó en honor a la memoria y familia del chofer.

Un tema mayor es el acoso sexual en buses. Froteurismos, intimidaciones, excesos mímicos, ademanes, lenguaje obsceno y otras patologías propias del abuso sexual patriarcal, se reporta a diario en vehículos de transporte público especialmente urbanos.

Dicha conducta es el reflejo de algo mucho más dramático. Es síntoma, preludio, efecto o concomitancia respecto de situaciones de mayor dimensión. Los feminicidios en lo que va del año 2017 se cuentan en 50, en menos de cinco meses de estadísticas nacionales. Mujeres asesinadas por quienes consideran ser de su propiedad.

Al abordar el tema del transporte público, no puede dejarse de lado al metro o subway. Parte de la vida cotidiana de las grandes ciudades, el metro es escenario de la esencia misma de la metrópoli y la megalopoli modernas. El metro de New York el primero y emblemático y el de San Petersburg y Moscú -sobre todo este último - de los más hermosos del mundo: cada estación, una verdadera galería de arte y un museo vivo.

"Don' t sleep in the subway" es una partitura y letra de Tonny Hatch y Jackie Trent, con la grabacion original de Petula Clark para la música pop; se convirtió desde abril de 1967 en una canción símbolo en recrear la relación de pareja y sus conflictos, teniendo como tela de fondo precisamente el subway:

"Don't sleep in the subway darling'

Don't stand in the pouring rain

Don t sleep in the subway darling'

The night is long

Forget your foolish pride

Noting is wrong

Now you're beside me again" (International Lyrics Playground)

El metro es una extensión del concepto del auto y del tren combinado. Carros sofisticados encarrilados en vagones generalmente subterráneos, con tecnología de punta, han transformado la vida urbana; vehículos desplazándose a gran velocidad a través de túneles, como topos dentro de las ciudades, son en efecto mega obras de ingeniería. 
Uno de los fenómenos recientes derivados del uso del metro y también de los buses es el denominado "manspreading", concepto que ha sido incorporado al Oxford English Dictionary desde el 2015. Se refiere a la situación generada por algunos varones usuarios, cuando al abrir sus piernas al sentarse invaden el asiento de sus vecinos. Podría interpretarse además no sólo como una postura relajada sino eventualmente como una mímica machista y obscena, mientras otros han defendido se debe a posturas fisiológicas derivadas de la anatomía y fisiología masculinas. Se han lanzado campañas para prevenir su práctica en los metros de New York y México. Incluso ha habido detenciones por ello. Persiste el debate sobre esta tendencia en donde inclusive el actor de cine Tom Hanks, ha sido acusado de practicarlo, aunque con su correspondiente defensa señalando que cuando ello ocurrió, el carro del metro iba vacío. Casos similares han exhibido tendencias virales a favor y en contra en las redes sociales.

"Shebagging", por su parte es el término complementario, dado para la situación de las mujeres que se toman otro espacio contiguo en el metro o buses, cuando invaden otro asiento contiguo con sus bolsos y carteras. (El Confidencial, 2017).

\section{Polución y ambiente.}

El Ecuador en los últimos años ha incrementado abrumadoramente su parque automotor. Problemas ligados al medio ambiente derivados de la emisión de gases de los vehículos, el ruido y la emisión de decibeles incompatibles con la salud y el bienestar, el aumento exponencial de accidentes en las rutas del país, incluidos algunos con efectos fatales y por otro lado, la búsqueda incesante apropiando innovaciones del mundo desarrollado para volver más seguro, más económico, más sustentable el entorno en relación a los vehículos automotores, han motivado a los claustros académicos a presentar proyectos de investigación, trabajos y artículos de alta calidad entorno a su particular área del conocimiento.

Aunque se debe tener presente que a pesar de que la tecnología avance para reducir este problema siempre va a existir contaminación ambiental gracias a los automóviles, ya que no solo los gases que emiten son los que causan daño sino también los desechos que provocan su devaluación; es un mal con el que debemos vivir puesto a que el auto es una herramienta que más que un lujo es una necesidad para el día a día de una población ${ }^{14}$.

Si bien es cierto, en la actualidad los vehículos contaminan mucho menos que los de hace algún tiempo atrás, el problema radica en que hay un aumento continuo de los mismos, por lo que aún la industria automotriz es una de las mayores responsables de la producción de $\mathrm{CO} 2$, y ésta es una batalla que aún no se termina de ganar, pese a que ahora se trabaja con muchos valores y principios, entre los que sobresale el respeto al medio ambiente ${ }^{15}$.

Resonancia mundial ocurrió hace unos meses cuando la fábrica Volkswagen fue descubierta por haber alterado el programa técnico para emitir resultados sobre el control de gases de sus vehículos. El gigante automotor alemán recibió una multa millonaria a pagar por

\footnotetext{
${ }^{14}$ Datos obtenidos mediante entrevista al estudiante de la carrera de Ingeniería Automotriz, Bruno Malisani

${ }^{15}$ Información otorgada mediante entrevista a docente investigador de la carrera de Ingeniería Automotriz de la UIDE Juan Fernando Iñiguez.
} 
dicha trampa. La fiscalía de EEUU solamente le impuso una penalidad de 4.500 millones de USD. Otras empresas y marcas no se han escapado de denuncias similares

Pito, claxon, bocina, sirena. Rastreando su semiótica.

El uso y el abuso del pito o claxon, permiten involucrarse en el estudio de la violencia y sus sustitutos. Una particular forma de insultar en las calles tiene un instrumento: el pito, que se convierte en el puño que no puede llegar a impactar en la anatomía del otro conductor, del peatón o del ciclista.

Se pita con distintos sonsonetes según la forma y el 'estilo' de canalizar la agresión. Se pita más si la víctima del encono del pito es una mujer. El claxon es una herramienta sustitutoria de la coprolalia, aunque el lenguaje obsceno y violento con frecuencia va acompañado de maltrato coordinado con el uso del claxon. Y el pito es más violento y rudo si el auto es más grande.

La bocina tiene lenguajes afectivos sin embargo, como la costumbre de saludar y congraciarse con peatones y otros conductores. Hay diversas formas de pitar, a veces en clave como símbolo de identidad de una jorga, de una pandilla. Aunque con variantes, también aquellos pitos contribuyen a generar polución por ruido en las ciudades. Modalidades de bocinas generaron innovadoras formas de producir silbatos que remedaban silbidos humanos, aderezados y dispuestos para cortejar y seducir. En el onomatopéyico 'fui-fuii-uuu', su sonido imita un silbido al servicio del erotismo y el cortejo sexual.

En la película, comedia a la italiana, que pertenece a las cintas denominadas de culto, 'Il sorpasso' (Riso, D. 1962), el protagonista Vittorio Gassman exhibe frente a Jean-Louis Trintignant un coche convertible blanco de estupenda belleza, dispuesto de un tocadiscos acoplado al auto como el último boom de la invención sonora. Un Lancia Aurelia B24 traía además una bocina coqueta y estrepitosa, símbolo de la vida fácil, la 'dolce vita', cuyo sonido juguetón servía para festejar e ironizar a su paso. La película termina en tragedia cuando el coche descapotado se precipita al fondo de un barranco.

Autos espectaculares como los Alfa Romeo Spider o Giulia o los Lancia Aurelia -con su diseño de la camisa de radiador en forma de escudo de guerrero, rectangular irregular y longitudinal- hipnotizaron siempre. La fina ironía del maestro del séptimo arte, Dino Risi, sobre los autos deportivos, sus riesgos y sombras, deja en los espectadores más de una mueca admonitiva a través de la mencionada película clásica.

'Por sus bocinas os conoceréis', se podría parafrasear. En efecto, así como el mecánico experto puede distinguir cada marca de vehículo por el sonido de cada máquina, incluso eventualmente de cada modelo de una marca, de similar manera hay técnicos con experiencia y buen oído, que pueden diferenciar cada marca de vehículo por su particular modo de sonar su bocina. Si bien ésta no es sino una pera insuflada de aire conectada a un parlante, cada marca aporta su propia identidad tocante a su pito con su particular tono y timbre -casi como lo que ocurre con infinita más complejidad con la voz humana-. 
En cuanto a sirenas, las hay propias de ambulancias y bomberos. Pero en manos de adolescentes más de otras épocas, hubo inventos graciosos en torno a variantes de sirenas, creados para chancear y vacilar al género opuesto. En otra parte de este trabajo se citó el caso de las aterrorizantes sirenas de la Gestapo nazi.

Por alguna razón el nombre de las sirenas de los autos, proviene del concepto mítico griego de las sirenas que atraían con sus cánticos a los incautos marinos para precipitarles sobre los riscos y peñascos del mar embravecido. Ulises supo evadir su encanto seductor, mientras Hans Christian Andersen reinventaba en nuevos tiempos el mito y el relato, con otro enfoque desde su Copenhagen natal.

En otras épocas los taxis tocaban su claxon más libremente y sin mayor censura ni recato. En efecto, una canción norteamericana de la década de los sesenta del siglo XX del celebrado conjunto pop 'Peter Paul and Mary', que en 1967 publicitaron letra y música a partir de una partitura de rock lento que se intitulaba 'Leaving on a Jet Plane'. En una parte romántica de ella se hacía relación a la ausencia del hogar de un asiduo viajero dejando su corazón roto, mientras en la calle un auto persistía con su claxon en recogerlo camino al aeropuerto. 'The taxi' s waitin'/ He' s blowin' his horn'.

Mientras crece la tendencia civilizada de abolir el claxon y dejarlo reservado para usos emergentes, persisten formas inmaduras y bárbaras de conducta frente al uso de la bocina. En algunas ciudades ecuatorianas, camiones y camionetas distribuidoras de bombonas de gas doméstico -con el quemeimportismo de sus alcaldes- anuncian su oferta comercial a domicilio, mediante el uso continuo y apabullante de pitos intermitentes y rítmicos escupidos en los barrios, que sólo reposan temporalmente cuando sus clientes se asoman a la vera de sus casas para comprar -cómplices con el ruido- su imprescindible tanque de gas licuado.

La búsqueda de ciudades silenciosas es aún una quimera. Sin embargo escuelas y colegios que miman la calidad ambiental en algunas partes, también en Quito, ya han impuesto como norma disciplinaria para conductores de busetas estudiantiles, que al recoger y al dejar a los alumnos a domicilio, el conductor esté prohibido de pitar. En lotizaciones y urbanizaciones cerradas, mientras se estimula el uso de citófanos privados, el pito espetado al ambiente sin escrúpulos tiende a desaparecer del diccionario de la convivencia civilizada.

Sin embargo ensayando otras lecturas, las sirenas empoderan. No solo comunican el flagelo de un incendio, una catástrofe o un paciente grave. Son herramientas que significan prestigio, exclusividad o al menos visibilidad. Quizá en un intento científico en donde se comparen tiempos y símbolos, el claxon, el pito, la sirena, la bocina, son remanentes de las salmodias de brujos, curanderos y shamanes de antaño, que comunicaban sonoramente también la detención de poder, conocimiento, vanidad, prestigio, exclusividad, respecto de aquellos personajes y sus ritos.

Una sutil forma de agresión consiste en usar otras formas de lenguaje simbólico, relacionado con el uso no técnico de las luces: cuando al conductor de un vehículo le interesa rebasar a otro, sobre todo cuando trae entre manos exceder el límite de velocidad permitido, entonces eleva las luces altas en forma reiterativa, para que a través de los espejos retrovisores el 
auto que lleva la delantera, ceda el carril al apurado carro. Claro que hay que conceder que no pocas veces los conductores lentos, abusan de utilizar los carriles izquierdos de las vías, reservados a los autos que circulan con más velocidad.

Más atrás de la vacuidad enervante del pito y sus derivaciones, siempre encontraremos viscosas hermenéuticas y más de una insólita semiótica.

El grito humano es otra forma de expresión y lenguaje del poder. Gritar supone ejercer una forma de autoridad. La terapia del grito primal por ejemplo supone una técnica de psicoterapia gestáltica mediante la cual el ejercer la liberación de las pulsiones, a través de la emisión de gritos controlados en el laboratorio, gritos a semejanza de los simios antecesores humanos, devienen en interesantes escenarios de terapias psicodinámicas.

El pito, claxon o la bocina y sirenas tienen vecindad semiótica con el grito humano. Grita el que manda. Sin duda que hay diferencias culturales. Hay culturas que gritan más como la caribeña. Hay otras, como las andinas que son más silenciosas. Alguna interpretación considera que los españoles conquistaron América gritando.

\section{El deporte tuerca, allende y aquende.}

Juan Manuel Fangio, Emerson Fittipaldi, son dos de los representantes latinoamericanos más emblemáticos de las carreras de pista en el mundo.

En la historia de los pilotos de ruta en el Ecuador, el ambateño Luis "loco" Larrea, el cuencano Arturo Semería, el guayaquileño Alberto Cucalón y los quiteños Alfonso Darquea, y Netucho Dávalos son parte de la memoria nacional. También el "Chino Sosa"16", a pesar de sus rasgos psicopatológicos duros al final de sus días, y otros veteranos de la rama, ofrecieron memorias perdurables a los públicos ávidos del vértigo de la velocidad y de la habilidad andina en sortear los vericuetos polvorientos de las rutas primitivas del Ecuador de entonces.

Son parte de los anales de la historia, las afamadas "Vueltas a la República", en donde en caminos más de polvo o piedra que de asfalto, la experticia de los pilotos criollos era incontrastablemente más difícil en muchos campos que lo que ocurre en la Fórmula 1. Durante los últimos decenios se ha suspendido en el país la organización de dichos desafíos; persisten algunas carreras locales como la del autódromo en torno a la laguna de Yaguarcocha en las cercanías de Ibarra, mientras en el mundo una suerte de maratón automovilística casi rayante en una odisea moderna todavía significa el Rally París-Dakar.

\section{El futuro gracias a la inteligencia artificial.}

La investigación relacionada con vehículos eléctricos cuyas baterías tengan larga vida, investigación sobre el aceite y su durabilidad, incursiones cada vez más evidentes en el mundo de producción de vehículos para marchar sin conductor humano, provocan pronósticos cada vez más renovados en la industria mundial de los vehículos.

\footnotetext{
${ }^{16}$ Referencia dada por el doctor Diego Pérez, decano de la facultad de Ingeniería Automotriz de la UIDE
} 
Históricamente la inteligencia artificial generó autonomía a los vehículos; es decir autos no conducidos por seres humanos, comenzó por temas militares con el VW Stanley en 2005 fabricado por la Universidad de Stanford para el abastecimiento de tropas, después de ganarse su estimación en una carrera internacional todo terreno de $210 \mathrm{~km}$, conocida como el Gran Desafío de Darpa.

Un segundo vehículo y más popular, un VW Passat, más conocido como Junior, fue también creado por esta universidad, el mismo que tuvo tanto éxito que estimuló posteriormente el crecimiento de este negocio lucrativo en esta área, lo que ha impulsado hasta la actualidad que algunos de los principales fabricantes posean una línea en este campo.

Un caso en particular es el de Nevada, USA, en donde en el año 2011 se aprobó la ley que impone al estado instaurar regulaciones que permitan que estos vehículos independientes puedan usar las vías públicas; tratándose por tanto de un ejemplo claro de inteligencia artificial en el transporte. (Diamantis \& Kotler, 2013).

En cuanto a la producción de autos eléctricos lleva el liderazgo europeo Noruega con 45 mil autos matriculados en el 2016. Le sigue el Reino Unido con 37 mil, más atrás Francia y Holanda. La tecnología trabaja intensamente en mejorar el tiempo de recarga de sus baterías pues aun toma cerca de 30 minutos cada nueva vez hacerlo. Además dichos autos son bastante más costosos. (DeutscheWelle, 2017).

Aportes cada vez más innovativos en varias marcas de partes y accesorios de automóviles lo tienen por ejemplo las marcas BOSCH, abastecedor mundial de tecnología y servicios como de baterías, bujías y otros equipos reconocidos a nivel mundial y TELSA, fabricante de autos eléctricos como también proveedora de tecnología y diseño con enfoque en el campo energético.

BOSCH aparte de ser fabricante, ha mantenido convenios con la UIDE, en los cuales ha ofrecido laboratorios y ha proporcionado pasantías internacionales para el aprendizaje de estudiantes de la carrera de Ingeniería Automotriz.

\section{El medio que extravió el fin.}

El mundo automotriz es apasionante en tecnología, utilidad y belleza. Una de las mayores esencias del siglo XX y comienzos del XXI. Mucho hay que investigar, innovar y a la vez prevenir para evitar que el hombre se encuentre al servicio de la máquina y no al revés, al menos en torno de los vehículos, que parece la vida refregarnos en paradoja. "El sábado al servicio del hombre y no el hombre al servicio del sábado" como sentenciaba Jesús en el Nuevo Testamento, durante su alegato contra los fariseos que le anatemizaban por hacer milagros en sábado, día sagrado y descanso obligatorio para los judíos. Pues en efecto también en nuestros días el auto debe ser un medio, que encauce el Sumak Kawsay. Jamás un fin per se.

Pero ya es hora de apagar el coche.

Sin embargo, ya es hora en efecto de apagar la máquina del coche. Solo concluir aseverando que varias instituciones han desarrollado programas preventivos para minimizar 
aquellas sombras y el lado oscuro de los autos, buscando una vocación humanística y proactiva. La Universidad Internacional del Ecuador- UIDE- ha cristalizado por ejemplo desde hace varios años su programa "No más corazones azules en la vía", donde ha coorganizado campañas nacionales en unión de COVIAL, con sensibilidad y eficiencia para prevenir los temibles accidentes automovilísticos en las rutas del país. Fue una iniciativa emprendida por el rector fundador y canciller de la universidad, una idea tomada originalmente de Colombia en la que tuvo un importante impacto en la conciencia nacional, queriendo los mismos resultados para nuestro país y que en efecto lo tuvo con la colaboración directa de la Policía Nacional, lográndose la conciencia y educación de los conductores con limitados obstáculos ${ }^{17}$.

Ecuador, 10 años de gobierno, en el cual se construyeron óptimas carreteras y autopistas, cuando la población estaba habituada a caminos angostos y defectuosos, donde la velocidad no era un factor preocupante, al gobierno le faltó la tarea de educar a la ciudadanía a transitar por estas nuevas vías que se desarrollaban cada vez más, lo cual tuvo como causa el aumento de accidentes automovilísticos, que después desencadenaron en una gran variedad de campañas en contra, como la mencionada anteriormente ${ }^{18}$.

\section{Conclusiones}

El desempeño del automóvil y en forma colateral el de otros vehículos motorizados afines, presentan aspectos amplios y variados, en constante y cambiante aplicación en diferentes momentos de la historia. El uso del auto ha sido complejo y ambivalente en la historia con distintos claroscuros. La humanización de la tecnología automotriz es un imperativo final sugerido, como una forma de superar el impacto paradójico entre el hombre y la máquina.

\footnotetext{
${ }^{17}$ El canciller de la UIDE, Marcelo Fernández comenta sobre esta iniciativa en una entrevista concedida.

${ }^{18}$ El canciller de la UIDE, Marcelo Fernández comenta sobre el origen del aumento de accidentes de tránsito en el Ecuador
} 


\section{Bibliografía}

Altima. (04 de abril de 2016). La muerte de Albert Camus. Recuperado de http://www.altimasfi.com/es/tanatopedia/la-muerte-de-albert-camus/

Automagazine. (2017).Automagazine.ec. El primer automóvil que circuló en Quito. Recuperado el 04 de mayo de 2017:http//automagazine.ec/ el-primer-automóvil-que-circulo-en-quito/

Avance. (2017).Ed, julio.Recuperado:http//www.revistavance.com/

Bekhrad, J. (2017). BBC Culture. Obtenido de El Zoroastrismo, la misteriosa religión que cambió a occidente, practicó Freddie Mercury e influyó en Game of Thrones.: www.bbc.com

Biblioteca Nacional de Chile (2016). Memoria Chilena. Recuperado el 04 de mayo de 2017 de: http://www.memoriachilena.cl/602/w3-article-763.html

Biografías y Vida. (2017). La Enciclopedia Biográfica en Línea. (2017). Recuperado el 05 de mayo de 2017 de: http://www.biografiasyvidas.com/biografia/s/senna.htm

Campaña, Isaías. C. (2017). Los 50 principales grupos económicos del Ecuador. Recuperado el 18 de mayo de 2017 de: http://lalineadefuego.info/2017/04/18los-50-pricipales-gruposeconómicos-del-ecuador-por-isaias-campana-c/

DeutscheWelle. (20 de abril de 2017). [TV] .Berlín.

DeutscheWelle. (30 de mayo de 2017). Sección Economía. [TV]. Berlín.

Diamantis, P., \& Kotler, S. (2013). Abundancia. Barcelona.

Donnersmark, F. v. (Dirección). (2006). La vida de los otros [Película].

Ecuador Profundo. (2017).Ecuadorprofundo.com. Recuperado el 04 de mayo de 2017: http://www.ecuadorprofundo.com/tomos/tomo4/e22.htm

El Comercio. (5 de febrero de 2017). Autos.

El Comercio. (09 de mayo de 2017). El modelo de negocio de los "food trucks" migró a los "food parks". Actualidad.

El Comercio. (02 de junio de 2016).En Ecuador no está prohibido tener relaciones sexuales en el auto.

El Confidencial. (08 de junio de 2017). 'Manspreading': qué es y por qué el despatarre masculino resulta insolidario. Recuperado de http://www.elconfidencial.com/alma-corazonvida/2017-06-08/manspreading-masculino-despatarre-hombres-metro-asientos_1395954/

El Pais.(2015).Recuperado:http//www.elpais.com/ 
El País. (29 de mayo de 2017). Los hombres cometen cinco veces más infracciones de tráfico por drogas que las mujeres. Obtenido de http://politica.elpais.com/politica/2017/05/26/actualidad/1495811877_439646.html?id_ex terno_rsoc=whatsapp

International Lyrics Playground. (s.f.). Don't sleep in the subway. Obtenido de http://lyricsplayground.com/alpha/songs/d/dontsleepinthesubway.shtml

Omicrono (2017). La historia detrás de Red Bull: Una marca que no crea, vende .. Recuperado el 09 de mayo de 2017: http://omicrono.elespanol.com/2013/10/la-historia-detras-de-redbull-una-marca-que-no-crea-vende/

Organización Mundial de la Salud. (2017). Lesiones causadas por el tránsito.Recuperado el 04 de mayo de 2017: http://www.who.int/mediacentre/factsheets/fs358/es/

Teleamazonas. (07 de mayo de 2017). [TV] .Ecuador.

Vallejo, R. (2016). El eterno exiliado. Penguin Random House. 


\section{Anexo 1}

\section{Entrevistas semi estructuradas.}

\section{Introducción.}

Se decidió levantar un grupo selectivo de entrevistas a distintos expertos en diferentes campos de la Ingeniería Automotriz. Algunos de ellos son docentes investigadores, otros a la vez figuran como cuadros directivos de gestión en las carreras mencionadas, un activista ciudadano, un dirigente universitario con vocación cívica que han trabajado altruistamente en tareas ligadas a la prevención de accidentes en las vías y un estudiante de nivel avanzado de la carrera indicada. Se les informó que sus respuestas y pensamientos servirán de insumos para la publicación de un paper en una revista indexada de calidad. Cada entrevista fue llevada a cabo en forma personalizada y física para cada uno de ellos excepto dos personas que usando el teléfono y el internet por encontrarse en otras ciudades, sus entrevistas fueron obtenidas. Por razones éticas ligadas a la investigación se les pidió autorización para que el fruto de sus entrevistas pueda ser publicado. El levantamiento de la información referida se realizó durante los meses de abril y mayo del 2017.

\section{Entrevistas:}

\section{Andrés Castillo (Coordinador y docente investigador de la carrera de Ingeniería Automotriz UIDE Matriz)}

\section{- ¿Cuáles han sido las principales innovaciones, descubrimientos o iniciativas que ha tenido la carrera de Ingeniería Automotriz en estos últimos tiempos?}

Básicamente nosotros nos hemos enfocado en la parte electrónica con respecto a los avances tecnológicos, porque el motor ha evolucionado más en la parte electrónica, más que todo se ha enfocado en el control de emisiones vehiculares. Los antiguos motores de combustión interna, los antiguos vehículos tenían un motor que contaminaba mucho. Esos parámetros no eran tan medibles o exigentes en esa época porque obviamente no había una cantidad grande de vehículos que circulaban; cada vez fue creciendo el parque automotor, cada vez que hubo más autos hubo más contaminación ambiental, por lo cual organismos ya gubernamentales de cada país, organismos internacionales crearon más normativas para regular esto, entonces pues vino el control electrónico a ser parte de una solución a lo que era la contaminación ambiental, entonces aquí la Ingeniería Automotriz ha ido evolucionando exclusivamente en la parte electrónica.

\section{- ¿Cuáles han sido los obstáculos que se han presentado en la carrera con respecto a la parte tecnológica?}

El no tener los equipos, las herramientas de diagnóstico a la mano, no hemos tenido nosotros la información o los equipos de primera mano en su momento; actualmente ya los tenemos pero como cada marca, cada vehículo saca su tecnología deberíamos tener nosotros actualizados nuestros vehículos, nuestras herramientas de diagnóstico para estar a la mano con todo lo que se viene en tecnología. Estamos hablando por ejemplo de vehículos que vienen 
netamente eléctricos, información de eso no existe más que tenemos que irla construyendo nosotros mismos, entonces la parte automotriz genera grandes adelantos, sin embargo las casas fabricantes son muy celosas de dar toda esa información. Esos son pequeños obstáculos, no le veríamos mucho como obstáculos realmente, y también la parte gubernamental, no está bien hablar de política pero sin embargo acá ha influenciado mucho en que nuestro país no ha tenido el desarrollo como debería tenerlo.

\section{Juan Fernando Iñiguez (Docente investigador Ingeniería Automotriz UIDE Matriz)}

\section{- ¿Cuáles son los principios y valores humanos que considera debe poseer un Ingeniero Automotriz?}

Sobre todo el ingeniero automotriz tiene que ser una persona muy creativa, como cualidad o característica de ingenio, pero si hablamos de valores humanos sobre todos los valores siempre está el respeto, porque el respeto, porque dentro del negocio automotriz siempre es necesario en la actualidad pensar en el medio ambiente por ejemplo, en la actualidad los fabricantes automotrices están pegados a normas muy fuertes de regulación, especialmente lo que es Europa, Japón y Estados Unidos, aquí no hemos tenido muchas normas de regulación tan fuertes medio ambientales, pero en otros países el respeto al medio ambiente es una tendencia cada vez mucho mayor y es una exigencia mucho más fuerte, entonces como ingenieros debemos siempre tener presente el respeto al medio ambiente desde la parte Ingeniería, más que desde la parte humana.

\section{- $\quad$ ¿Considera que la industria automotriz puede atentar contra el entorno natural y humano?}

Definitivamente sí, la irresponsabilidad con el medio ambiente puede ser muy grande en la industria automotriz; de hecho los primeros años de los vehículos colaboraron a lo que actualmente cosechamos que es el problema de la capa de ozono o del calentamiento global, entonces uno delos más grandes factores de $\mathrm{CO} 2$ del planeta son los automóviles y esto es una batalla que la industria automotriz todavía no acaba de ganar. En la actualidad las reducciones son menores debido a los controles que existen y a la tecnología, pero obviamente si bien es cierto los automóviles en la actualidad contaminan mucho menos, pero hay mucho más volumen, entonces seguimos siendo los uno de los mayores productores de $\mathrm{CO} 2$, y en cuanto al uso de hidrocarburos, aceites por ejemplo en la industria del servicio, si no se da un tratamiento adecuado podemos tener graves consecuencias.

Sandra Chasi (Docente investigadora Ingeniería Automotriz UIDE Matriz)

\section{- ¿Cuáles son las ventajas de tener mujeres que enseñen y estudien la carrera de Mecánica Automotriz?}

Yo pienso que principalmente es un mito que las mujeres no estamos predispuestas a aprender carreras técnicas, esto ha cambiado con el tiempo más o menos desde el año 2000, hay mujeres que incursionan ya en la parte automotriz sobre todo en ensambladoras que son en donde principalmente se incursiona haciendo trabajos netamente operativos, para luego ir a ocupar puestos de supervisión o puestos gerenciales, yo creo que la misma sociedad no ha 
permitido que las mujeres incursionen sin embargo pienso que el papel de la mujer es muy importante porque al tener características como ser un poco más detallistas, un poco más suspicaces en encontrar defectos de autos, en encontrar vías de soluciones, las mujeres tienen una importancia muy loable en el sector automotriz más bien que tiene que seguir creciendo.

\section{- ¿Qué conflictos considera que se dan en el estudio y posteriormente en el mundo} laboral en una mujer que eligió la carrera de Ingeniería Automotriz?

Principalmente hay un problema social, y el problema social es que aún existe mucho machismo, incluso desde sus compañeros, no todos aceptan tener mujeres que estudien este tipo de carreras, otro de los puntos también radica en los mismos docentes también, he escuchado comentarios muy feos diciendo," no te quieren en la cocina por eso estas aquí", que sin duda van marcando la carrera de las personas, entonces yo siempre le digo a mis alumnas que las mujeres tenemos dos trabajos: el uno de decir que sabemos y el otro de mostrar que sabemos, cuando eso no pasa con los hombres, los hombres solo tiene que decir que saben y no necesariamente demostrar. En el mundo laboral hay muchas restricciones, porque he visto muchos anuncios por ejemplo que están contratando personas para trabajar en la parte de posventa y te dicen "hombre", sin saber nada te discriminan totalmente aun a sabiendas que hay muchas mujeres también preparándose para eso, también el sueldo es diferenciado, como también el trato en el caso de posventa. A mí me pasó porque yo fui subgerente de BMW en el que te decían "necesito hablar con alguien que sepa", la misma sociedad te juzga pensando que no sabes entonces toca demostrar que sabes para ganarte la confianza de los clientes, entonces es algo con lo que hay que luchar también.

\section{Edwin Puente, (Coordinador y docente investigador, carrera de Ingeniería Automotriz UIDE extensión Guayaquil).}

\section{- ¿Ve usted una ventaja comparativa para la acogida de la carrera de Ingeniería Automotriz en la costa y particularmente en Guayaquil?}

Al nombrar ventaja comparativa debemos tomar en cuenta principalmente el número de habitantes que la zona de la costa del país posee y comparando con Guayas posee más de tres millones de habitantes, siendo la primera provincia más poblada del Ecuador, seguida de Pichincha con casi 2 millones y medio de habitantes, y luego por Manabí con cerca de un millón trescientos mil habitantes. Es por ello que la ventaja comparativa entre estas provincias evidencia que la carrera de Ingeniería Automotriz en la costa es primordial tenerla, además que en Guayaquil siendo el principal puerto del Ecuador ya existe por más de 9 años en la Universidad Internacional del Ecuador la Facultad de Ingeniería Automotriz, en la cual se ha verificado el deseo que la comunidad tiene en aprender la carrera para poder mejorar su futuro.

En lo que se refiere a la comparación con la venta de vehículos, según la AEADE, la Asociación de Empresas Automotrices del Ecuador, Guayas finalizó con una participación en el 2016 del 28\%, quedando en segundo lugar a nivel país. Dentro de esta misma información también analizamos la importancia de tener esta carrera por la cantidad de vehículos matriculados a finales del 2016 con una cantidad de 576.928 automóviles, generando así varías plazas de trabajo en este campo en el servicio posventa y todas sus esferas de actuación. 


\section{- ¿En que influyen las características regionales de la costa para elegir la carrera de Ingeniería Automotriz?}

Las características regionales de la costa se ven reflejadas directamente en la transportación marítima comercial que tiene como centro el puerto de Guayaquil y que para su actividad que constituye el de mayor salida de las exportaciones nacionales, como las exportaciones industriales a nivel de país provienen de actividades agro industriales con mínimo valor agregado y que en general todas éstas necesitan del servicio de transporte terrestre en todos sus niveles. Figuran, asimismo, varios puertos privados que incrementan el movimiento comercial en la zona del estuario de Guayaquil que han convertido a Guayaquil en la capital económica del Ecuador. Además el considerar los temas climatológicos por el efecto de estar a nivel del mar donde tenemos mayor presencia de oxígeno y los motores de combustión desarrollan su trabajo con mayor efectividad y performance, en el que se puede desarrollar varias pruebas e investigaciones para contribuir con el medio ambiente. Éste es el caso de la Universidad Internacional del Ecuador con su Facultad de Ingeniería Automotriz la cual aprovecha estas características de la zona para poder comprobar mediante un dinamómetro las potencias y las torques de los vehículos que llegan a esta Facultad.

\section{Marcelo Fernández (Rector fundador, canciller UIDE).}

- ¿Cuáles considera que fueron los puntos positivos de la Iniciativa fundada por usted junto con COVIAL respecto a las campañas de tránsito: Las Tarjetas (Gracias por respetar la ley - No hagas esto) y No Más Corazones Azules En Las Vías?

En diciembre del 2003, día que dejó la alcaldía Antanas Mockus lo visité en su despacho con quien compartimos sus experiencias como rector general de la Universidad Nacional y como alcalde de la ciudad. Antanas Mockus por su experiencia académica creyó mucho en las campañas de participación ciudadana para lograr cambios voluntarios de comportamientos colectivos, habiendo implementado decenas de campañas persuasivas como alcalde de la ciudad durante los dos períodos que la ejerció: referente a la recaudación de impuestos, ahorro voluntario de agua, higiene de la ciudad, Bogotá Coqueta, Campaña del voto vital, etc. Concretamente en relación al tránsito realizó dos campañas: una de las tarjetas y el otro sobre como disminuir la violencia en las vías.

Por mi lado, le expliqué que la Universidad Internacional del Ecuador (UIDE) y la Corporación de universidades Particulares del Ecuador (CEUPA) realizaron en el país una campaña de la NUEVA HORA ECUATORIANA, persuadiendo la puntualidad y lo mucho que perdía el país en recursos financieros por la informalidad, a Mockus le pareció muy interesante y dijo que luego con su empresa sin fines de lucro denominada Corporación Visionarios por Colombia (Corpovisionarios) tendría en cuenta para realizarla, más aun me pidió que envíe a un funcionario para que explique a sus colaboradores los adentros de la campaña y efectivamente Gabriela Zuñiga, coordinadora de CEUPA y colaboradora de la UIDE fue a Bogotá durante una semana. 
En relación a las campañas de tránsito, el alcalde Mockus con funcionarios de la alcaldía me dieron los adentros de dos campañas sobre el tema: la de las tarjetas y la que denominaban “¿Qué nos pasa?”. La primera la adaptamos en Ecuador haciéndola un poco más grande que decía: GRACIAS por respetar la LEY y al reverso de la tarjeta NO hagas ESTO! Imprimimos dos millones y medio de tarjetas que conjuntamente con COVIAL las repartimos a nivel nacional, incluyendo Galápagos, fue una campaña muy alegre que dio grandes resultados. Los volantes de los automóviles, buses y camiones la usaban con entusiasmo causando risas en vez de disgustos entre los conductores de automóviles y transeúntes. Cuando hacían bien les sacaban la tarjeta de "GRACIAS por respetar la LEY" y cuando el otro conductor o transeúnte no respetaba las reglas de tránsito le sacaban la tarjeta de "No hagas ESTO!".

Luego de iniciada nuestra campaña, diversas alcaldías del país como son las de Guayaquil, Loja, Ambato, etc. adoptaron la campaña de las tarjetas con una gran repercusión nacional.

La segunda campaña que la iniciamos con COVIAL, la denominamos "No más corazones azules en las vías", que consistía en pintar las calles del país donde había habido un accidente de tránsito que causaba muertes. Como estas dos instituciones carecían de recursos, no pudimos hacerla muy extensiva y por fortuna la Policía Nacional liderada en esa época por Juan Zapata asumió esta campaña, la cual tuvo un renombre en todo el país por lo bien que se la hizo.

Un comentario adicional sobre el tránsito en el Ecuador, el gobierno de Rafael Correa durante sus primeros siete años de gobierno construyó excelentes autopistas y carreteras, a las cuales los ecuatorianos no estábamos acostumbrados, pues en el pasado gran parte de nuestras vías teníamos caminos antiguos, estrechos y pocas autopistas por lo cual no se podía ir a mayor velocidad y de esta manera había menos accidentes de tránsito. Cosa similar ocurre en la India, donde por lo congestionado del tráfico en caminos y carreteras la velocidad máxima de los vehículos es de $60 \mathrm{~km} / \mathrm{h}$, por lo tanto hay pocos accidentes. En cambio en el Ecuador en las carreteras y en las vías como la Av. Simón Bolívar en Quito, la Occidental o la Perimetral en Guayaquil hay graves accidentes y muertes. Al gobierno de Rafael Correa se le olvido hacer campañas educativas de tránsito para que los conductores no abusen de la velocidad o conduzcan con exceso de alcohol o estupefacientes.

\section{- ¿Cuáles considera que fueron las desventajas o conflictos que tuvo la iniciativa de esta campaña?}

Desventajas ninguna, yo creo que como desventaja no hay, conflicto como siempre, la oposición de la gente que no creía en esto, pero casi no ha habido desventajas, la mayor parte son ventajas.

Víctor Jiménez (Director Ejecutivo de la Fundación Covial)

- ¿Cuáles Considera Que Fueron Los Logros Con La Iniciativa Impulsada Por Usted Sobre La Campaña No Más Corazones Azules En Las Vías? 
En Quito se redujeron los accidentes entre los años 2004-2005 en un 2\%, se pudieron salvar 42 vidas. Fue una campaña muy reconocida que después se unió con conciertos de artistas nacionales que aportaron su talento para enviar un mensaje de vida y transmitirlo a través de la música; después la campaña llegó al interés de diferentes países como como Colombia, Argentina, España entre otros.

COVIAL contribuyó a la reducción de mortalidad por tránsito, pero estuvo muy lejos de llegar a la conciencia de los usuarios viales. Si no se ataca el problema jamás veremos mejoras; el $96 \%$ de los siniestros en accidentes de tránsito es por causa del factor humano porque todos en el Ecuador estamos acostumbrados a hacer lo que nos viene en gana en cuanto a la conducción; si el factor humano no cambia nada va a cambiar; dicen que cuando una persona es inculta en la seguridad vial es inculta también en el quehacer diario de su pueblo y si esto no cambia tendremos aún 13 muertos por día y 152 heridos en las vías y seguiremos siendo el séptimo país en el mundo con mayores tasas de accidentes y el segundo en Latinoamérica.

\section{- ¿Cuáles considera usted que son los motivos que impulsaron la creación de esta campaña?}

El motivo primordial fue la intención de reducir los accidentes que reinaban en Quito. No más corazones perdidos en las vías tiene dos etapas: la primera fue de índole racional que se lanzó en mayo llamada: "Maneje con la cabeza", la segunda etapa fue de índole emocional, que apeló a la sensibilización, de enviar un mensaje al usuario viario es decir, al conductor al ciclista al peatón a que por sí solo practique la seguridad vial y use las vías de buena manera.

Rosa Correa de COVIAL, experta en publicidad fue la persona que conceptualizó las ideas y trató de enlazarlas; ella hizo el contacto con la Dirección Nacional de Tránsito con Juan Zapata quienes se interesaron con la idea, la hicieron suya y decidieron lanzar la campaña en Quito con la primera fase.

COVIAL trabaja en conjunto con la Dirección Nacional de Tránsito en la producción de spots para la campaña en los cuales, personajes como María Susana Rivadeneira, ex reina de Quito, Alex Aguinaga futbolista de fama internacional entre otros, participaron en dichas producciones. La Campaña "Maneja con la cabeza "duró un año, mientras que "No más corazones perdidos en las vías "duró más años. La UIDE, siempre estuvo presente en la campaña siempre estuvo en toda la lucha con su iniciativa de las tarjetas, ("GRACIAS por respetar la Ley" y "No hagas Esto!".

\section{Diego Pérez (decano y profesor investigador de la carrera de Ingeniería Automotriz UIDE Matriz).}

- ¿Cuáles son según sus investigaciones y experiencia como decano dela Facultad de Ingeniería Automotriz, las principales razones que permiten la retención de los estudiantes mientras cursan su carrera escogida?

Los trabajos de Investigación que he realizado en relación directa a la Facultad de Ingeniería Automotriz son dos: 
$>$ La influencia de las Variables pre-universitarias en la Retención Estudiantil hasta la graduación

Mujeres en la Facultad de Ingeniería Automotriz de la UIDE: Como asegurar su permanencia

La carrera de Ingeniería Automotriz atrae a chicos/as apasionados por el automovilismo. No necesariamente la mayoría de los postulantes llegan a la UIDE con una formación de educación secundaria en áreas de ciencias exactas lo cual constituye una barrera a superar por parte de los estudiantes una vez ingresados a la carrera. Sin embargo, esa pasión por conocer más sobre automotores es lo que les engancha y motiva a continuar, pues ven mucho futuro en sus carreras profesionales dentro de esta industria y de lo que los negocios satelitales a ésta que conlleva. Otra fortaleza en la optimización de la retención es el seguimiento personalizado realizado por parte de la administración de la Facultad en conjunto con el Departamento de Bienestar Estudiantil con estudiantes en riesgo, mismos que son inicialmente identificados por su bajo rendimiento académico. Una oportuna intervención con estos estudiantes permite rescatarlos y motivarlos a que continúen con su formación profesional dentro de la carrera. Una de las estrategias que en este sentido más funciona es la implementación del "Learning Center" en el cual se implementa un método de enseñanza colaborativa, muy exitoso para la retención de estudiantes.

\section{- ¿ ¿ las razones para la deserción de los estudiantes en la misma carrera?}

Existen muchas razones para la deserción estudiantil. Las principales de éstas pueden estar relacionadas a varios factores principales: académicos, psicológicos, sociales y de integración, y financieros. Cada uno de éstos es tratado individualmente y a través de departamentos especializados. El objetivo de la institución y de la facultad es lograr que sus estudiantes estén libres de presiones de cualquier índole para lograr su enfoque exclusivo en sacar provecho de la experiencia universitaria y por consiguiente exitosa en el área académica. Dentro del estudio sobre las mujeres en la facultad de Ingeniería Automotriz, fue muy interesante encontrar, contrario a las hipótesis, que ellas se sienten muy a gusto en un entorno primordialmente masculino, al sentirse especiales y protegidas por sus compañeros. Esto minimiza de muchas maneras la deserción de mujeres dentro de la carrera.

\section{Bruno Giuseppe Malesani Limongi (Estudiante, 6to semestre, carrera de Ingeniería Automotriz UIDE Matriz).}

\section{- Su opinión sobre los puntos positivos y negativos del automóvil para la sociedad.}

Como punto positivos, es que es una herramienta para todas las personas para movilizarse, creo que eso es básicamente lo más importante, por otra parte creo que ahora es un problema que existe mucha dependencia del mismo, lo cual trae consigo contaminación y aunque se intentan desarrollar nuevas tecnologías, siempre van a existir conflictos y no únicamente en los gases, sino también en aceites, desperdicios. Por ejemplo, se cambian las llantas, no se hace un correcto tratamiento sobre ellas porque ya no funcionan después o ya no sirven, y ello causa 
contaminación. Más que empezar a desarrollar esto se debe inculcar a las personas una idea de usar medios alternativos, el problema aquí, en nuestro país, es que las distancias para llegar de un punto a otro son relativamente largas y usar otros medios es difícil.

\section{- Si usted pudiera recomendarles a los directivos de su facultad que deberían cambiar en el pensum (syllabus) ¿Qué dirías?}

Puede ser que se tengan más convenios para empezar a hacer las prácticas, el problema es que ahorita está un poco saturado por el tema del país que es complicado, pero creo que el hacer prácticas realmente concientiza, pues falta aún bastante. Pienso que se debe impulsar más. Estudiar temas más específicos, más precisos y tener materias más prácticas para ser profesionales.

\section{Anexo 2}

\section{Análisis Sistema Antiplagio URKUND}

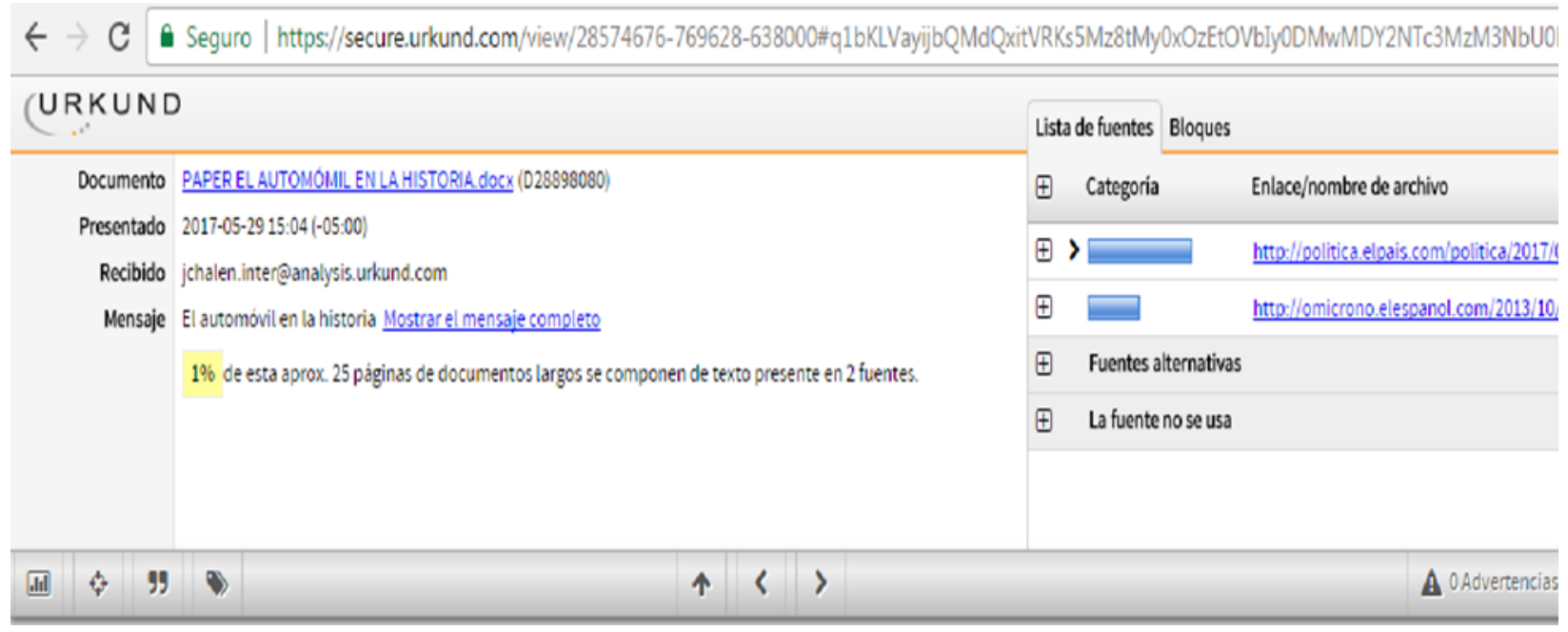


El Comercio. (09 de mayo de 2017). El modelo de negocio de los "food trucks" migro a los "food parks". Actualidad.

El pais. (2015).Recuperado:http//www.elpais.com//

\begin{tabular}{|l|l|l|}
\hline $100 \%$ & $=1$ Activo & Fuente externa: http: //politica.elpais.com/politica/2017/05/26/actua \\
\hline Los hombres cometen cinco veces más infracciones de tráfico por drogas que las mujeres. & Los hombres cometen cinco veces más infracciones de trafico por dro \\
\hline
\end{tabular}

Obtenido de

http://politica.elpais.com/politica/2017/05/26/actualidad/1495811877_439646.html?

id_externo_ rsoc=whatsapp

Omicrono (2017). La historia detrás de Red Bull: Una marca que no crea, vende .

Recuperado el 09 de mayo de 2017: http://omicrono.elespanol.com/2013/10/la-historia-detras-de-red-bulluna-marca-que-no-crea-vende/

Organizacion Mundial de la Salud. (2017). Lesiones causadas por el tránnito. Recuperado el 04 de mayo de 2017: http://www.who. int/mediacentre/factsheets/fs358/es/

Teleamazonas. (07 de mayo de 2017). [ TV] Ecuador.

Vallejo, R. (2016). El eterno exiliado. Penguin Random House. 